\title{
Identification of genes directly responding to DLK1 signaling in Callipyge sheep
}

\author{
Hui Yu Y $^{1,2^{*}}$ D, Jolena N. Waddell ${ }^{1,6}$, Shihuan Kuang ${ }^{1,3}$, Ross L. Tellam ${ }^{4}$, Noelle E. Cockett ${ }^{5}$ and Christopher A. Bidwell ${ }^{1 *}$
}

\begin{abstract}
Background: In food animal agriculture, there is a need to identify the mechanisms that can improve the efficiency of muscle growth and protein accretion. Callipyge sheep provide excellent machinery since the up-regulation of $D L K 1$ and RTL1 results in extreme postnatal muscle hypertrophy in distinct muscles. The aim of this study is to distinguish the genes that directly respond to DLK1 and RTL1 signaling from the genes that change as the result of muscle specific effects.

Results: The quantitative PCR results indicated that DLK1 expression was significantly increased in hypertrophied muscles but not in non-hypertrophied muscles. However, RTL1 was up-regulated in both hypertrophied and nonhypertrophied muscles. Five genes, including PARK7, DNTTIP1, SLC22A3, METTL21E and PDE4D, were consistently coexpressed with $D L K 1$, and therefore were possible transcriptional target genes responding to $D L K 1$ signaling. Treatment of myoblast and myotubes with DLK1 protein induced an average of 1.6-fold and 1.4-fold increase in Dnttip1 and Pde4d expression respectively. Myh4 expression was significantly elevated in DLK1-treated myotubes, whereas the expression of Mett/21e was significantly increased in the DLK1-treated myoblasts but reduced in DLK1treated myotubes. DLK1 treatment had no impact on Park7 expression. In addition, Park7 and Dnttip1 increased Myh4 and decreased Myh7 promoter activity, resemble to the effects of Dlk1. In contrast, expression of Mett/21e increased Myh7 and decreased Myh4 luciferase activity.

Conclusion: The study provided additional supports that RTL1 alone was insufficient to induce muscle hypertrophy and concluded that DLK1 was likely the primary effector of the hypertrophy phenotype. The results also suggested that DNTTIP1 and PDE4D were secondary effector genes responding to DLK1 signaling resulting in muscle fiber switch and muscular hypertrophy in callipyge lamb.
\end{abstract}

Keywords: DLK1, RTL1, Skeletal muscle, Hypertrophy, Callipyge sheep, Primary effector, Secondary effector

\section{Background}

Callipyge sheep are well known for their postnatal muscle hypertrophy that is prominent in loin and hind quarters [1-3]. The muscle mass in callipyge sheep is increased $35-40 \%$ and carcass fat is decreased 6-7\%, while the live weights are the same relative to normal lambs [3-6]. Callipyge lambs are born with normal muscling and hypertrophy becomes detectable at 46 weeks of age $[2,4,7,8]$. After 5 weeks of age, an increased proportion and larger size of fast-twitch, glycolytic muscle fibers become apparent in callipyge muscles $[7,9]$. Not all the skeletal muscles in callipyge

\footnotetext{
*Correspondence: huiyuz@umich.edu; cbidwell@purdue.edu

${ }^{1}$ Department of Animal Sciences, Purdue University, 270 South Russell Street, West Lafayette, IN 47907, USA

Full list of author information is available at the end of the article
}

sheep develop hypertrophy, the supraspinatus and infraspinatus muscles in thoracic limbs both do not undergo hypertrophy $[1,5,6]$.

The callipyge mutation is a single base change of an A (wild-type allele) to a $\mathrm{G}$ (callipyge allele) between $D L K 1$ (Delta-Like homolog 1) and MEG3 (Maternal Expressed Gene 3) genes in the DLK1-DIO3 (Deiodinase, Iodothyronine, type III) imprinted gene cluster [10, 11]. The callipyge mutation does not disrupt the protein coding sequence. The highly conserved 12 bp sequence including the mutation acts as a long-range control element to alter the transcription of the surrounding imprinted genes in cis. Specifically, the inheritance of a callipyge allele from the sire up-regulates the transcription of the paternal protein-coding genes DLK1 and RTL1 (Retrotransposon-like 1), while the inheritance of a maternal

(c) The Author(s). 2018 Open Access This article is distributed under the terms of the Creative Commons Attribution 4.0 International License (http://creativecommons.org/licenses/by/4.0/), which permits unrestricted use, distribution, and 
callipyge allele enhances the expression of maternal non-coding RNA including MEG3, MEG8 (Maternal Expressed Gene 8) and RTL1AS (RTL1 antisense) [12$16]$. As the muscling phenotype is only expressed in heterozygous individuals that inherit the mutation from the sire, it has been concluded that a paternally expressed protein encoding gene(s) must be the primary effector.

$D l k 1$ encodes a transmembrane protein belonging to the epidermal growth factor (EGF)-like repeat containing family. It functions as an antagonist to down-regulating Notch signaling $[17,18]$. Notch signaling is involved in conserved cell fate decisions and is known to inhibit the expression of myogenic regulatory transcription factor $M y o D$ and myogenic differentiation, but enhances satellite cell proliferation and self-renewal [19, 20]. Several studies indicate that $D l k 1$ expression can influence postnatal muscle growth. Transgenic mice over-expressing $D l k 1$ had increased muscle mass and myofiber diameter [21]. Similarly, mice with deletion of the maternal microRNA379/544 cluster displayed muscle hypertrophic phenotype with an elevation of $D l k 1$ expression, suggesting the regulation of maternal imprinted microRNA on paternal $D l k 1$ gene expression [22]. Muscle-specific gene ablation of $D l k 1$ in the mouse resulted in reduced body weight and skeletal muscle mass due to reduction in myofiber numbers [23]. Conversely, over-expression of $D l k 1$ in cell culture inhibited myoblast proliferation and enhanced differentiation [23]. DLK1 mRNA was up-regulated in longissimus dorsi, gluteus medius and semimembranosus, the hypertrophied muscles in callipyge lambs but not upregulated in supraspinatus, the non-hypertrophied muscle $[13,15,24,25]$. The DLK1 protein was expressed at high levels in the myofibers of callipyge longissimus dorsi and semimembranosus but was not detected in normal muscles $[26,27]$.

Similar to DLK1, the mRNA abundance of RTL1 is also increased in the callipyge muscles. Rtl1 belongs to Ty3-Gypsy retrotransposons gene family and contains gag-pol-like structure common to retroviruses [28]. This highly conserved gene has a single exon and encodes a full length $151 \mathrm{kDa}$ protein in callipyge skeletal muscles [29]. In mouse, Rtl1 is highly expressed at the late-fetal stage in both fetus and placenta and the loss or overexpression of Rtl1 causes late fetal and / or neonatal lethality [30]. Enhanced expression of Rtl1 in liver has been suggested to drive hepatocarcinogenesis [31]. Interestingly, transgenic mice expressing ovine RTL1 in skeletal muscle have significant increased mass of hind legs and quadriceps with larger myofibers in EDL (mostly composed of glycolytic fast twitch fibers) muscle [32]. However, in callipyge sheep, the up-regulation of RTL1 is not specific to hypertrophied muscles, a lower magnitude of induction of RTL1 in the non-hypertrophied muscle (supraspinatus) was detected [13], suggesting that RTL1 alone is not the primary inducer for increased muscle mass in callipyge sheep. These combined studies suggest that elevated $D L K 1$ expression is the primary cause of callipyge muscle hypertrophy and RTL1 probably has a synergistic effect with $D L K 1$.

MEG3, MEG8, and RTL1AS are all non-coding RNAs that are transcribed from the maternal chromosome in the same imprinted region. These genes are host to a number of microRNA and snoRNA (MEG8) [33]. Murine Meg3 was proposed to possess tumor suppressor properties [34-36] and extensive studies have been conducted recently to explore the mechanisms on how Meg3 inhibits cell growth [37-41]. Enhanced Meg3 expression was reported in obese mice and it further aggravated glucose intolerance in these mice [42]. Furthermore, during postnatal muscle development, Meg3 expression level was high after birth, however, it decreased rapidly afterwards in both pigs and mice [43, 44 ], implying its possible role in the growth of myofibers through hyperplasia instead of hypertrophy in late developmental stages [44]. In contrast to Meg3, there are few studies performed on Meg8. It is known that Meg8 was expressed in embryonic brain and muscles [45]. Maternal nutritional status significantly influenced MEG8 expression in fetal semitendinosus muscle in sheep [46, 47]. Temple syndrome patients have hypermethylated region in MEG8 gene [48, 49]. Nevertheless, knowledge about the exact function of MEG8 still remains unclear. Rtllas contains at least four microRNA that cause RISCmediated degradation of Rtl1 transcripts [50, 51]. As a result, deletion of miR-127 (one of the microRNAs processed from Rtllas) increased Rtl1 expression, leading to placentomegaly and defects in the placental labyrinthine zone [52].

Several studies have been conducted to identify transcriptome changes in the muscles of callipyge animals [24, $25,53]$. Microarray analysis of gene expression in the semimembranosus identified 375 genes that were differentially expressed in callipyge versus normal lambs [24]. Twenty-five transcripts were further verified by quantitative PCR [24]. It has been assumed that among these 25 transcripts, there are direct targets of $D L K 1$ signaling that act as secondary effectors to increase protein accretion and fiber type changes (tertiary responses) that occur during hypertrophy. The current study will distinguish the genes that appear to respond to $D L K 1$ signaling from tertiary effects of hypertrophy (see schematic diagram, Fig. 9a), using a broader set of hypertrophied and nonhypertrophied muscles at an age when hypertrophy is developing in the callipyge lamb. Genes that are transcriptionally responsive to $D L K 1$ signaling would be expected to have a similar mRNA expression pattern as $D L K 1$ in all the muscle types examined. In contrast, the tertiary responsive genes may not stringently follow the 
DLK1 expression pattern. These tertiary response genes could show greater variability across muscle types due to differences such as metabolism, myofiber types and exercise. From this initial screening of candidate genes, the effect of DLK1 as a ligand and transfection of target genes were tested using primary mouse myoblasts to confirm transcriptional activities in myogenesis. Since part of the callipyge hypertrophy phenotype includes a shift to a greater number of fast-twitch, glycolytic muscle fibers expressing $\mathrm{MYH4}$, then changes in MYH4 expression was chosen as an indicator of a tertiary response.

\section{Methods}

\section{Sample collection}

Matings between a ram that was heterozygous for the callipyge allele and a group of normal ewes were used to generate a cohort of callipyge and normal lambs. The lambs were genotyped by detection of the callipyge SNP $[10,11]$ and tissue samples were obtained from four callipyge and four normal lambs at 30-35 days of age following protocols approved by Purdue University Animal Care and Use Committee. Seven muscles (longissimus dorsi, semimembranosus, semitendinosus, triceps brachi, supraspinatus, infraspinatus, and heart) were weighed after dissection. A small piece of sample was preserved in RNAlater (ThermoFisher Scientific, PA, USA) and stored at $-20{ }^{\circ} \mathrm{C}$ for further RNA extraction. Muscle samples were homogenized in $4 \mathrm{M}$ guanidinium thiocyanate, $25 \mathrm{mM}$ sodium citrate, $50 \mathrm{mM}$ EDTA, and $1 \%$ sodium-N-lauroyl-sarcosine. The $\mathrm{CsCl}$ ultracentrifuge method was used to isolate RNA. Briefly, the muscle homogenate was centrifuged through a $\mathrm{CsCl}$ cushion $(5.7 \mathrm{M}$ $\mathrm{CsCl}, 50 \mathrm{mM}$ EDTA) and the sedimented RNA was further purified using NucleoSpin RNA II columns (Machery-Nagel, PA, USA) with Dnase I treatment [25].

\section{Primary myoblast isolation and culture}

Primary myoblasts were isolated from hind limb skeletal muscles of mice at 3-5 weeks of age. Muscles were washed with Dulbecco's Phosphate-Buffered Saline (DPBS), minced and digested in type I collagenase and dispase B mixture (Roche Applied Science, Indianapolis, IN USA). The digested muscle pulp was then filtered through a $100 \mu \mathrm{m}$ filter (CellTrics, Partec Inc., Swedesboro, NJ USA) to remove large muscle fiber debris and then plated on collagen-coated dishes. After 3 days, cells were collected and digested with $0.025 \%$ trypsin for $10 \mathrm{~min}$ with agitation. Cells were seeded in growth media (F-10 Ham's medium supplemented with $20 \%$ fetal bovine serum, 100 units $/ \mathrm{mL}$ of penicillin, $100 \mu \mathrm{g} / \mathrm{mL}$ of streptomycin, $0.292 \mathrm{mg} / \mathrm{ml}$ of Lglutamine, and $4 \mathrm{ng} / \mathrm{mL}$ basic fibroblast growth factor) on non-coated plates for $45 \mathrm{~min}$ to deplete fibroblasts, as previous described $[23,54]$ and then transferred to collagen (Roche Applied Science)-coated dishes. Myoblasts were differentiated into myotubes after plating cells at approximately $80 \%$ confluency on Matrigel (BD Biosciences, San Jose, CA USA) coated plates and the addition of fusion media consisting of DMEM supplemented with $5 \%$ horse serum, 100 units $/ \mathrm{mL}$ of penicillin, $100 \mu \mathrm{g} / \mathrm{mL}$ of streptomycin, and $0.292 \mathrm{mg} / \mathrm{ml}$ of L-glutamine. Myoblast cultures testing the effects of DLK1 protein were plated on a bed of $1 \mathrm{mg} / \mathrm{mL}$ BD Matrigel containing $500 \mathrm{ng} / \mathrm{mL}$ of recombinant DLK1 protein [DLK1 (mouse): Fc(human), Adipogen International Inc., San Diego CA USA. Cells were induced to differentiate the next day and fused for 2 days before mRNA isolation.

\section{Quantitative PCR analysis}

Complimentary DNA (cDNA) synthesis for measuring RTL1 transcript abundance used gene-specific priming of $5 \mu \mathrm{g}$ total RNA and Superscript III reverse transcriptase at $50{ }^{\circ} \mathrm{C}$ (Life Technology). The cDNA synthesis for other transcripts used random hexamer priming from $5 \mu \mathrm{g}$ RNA and MMLV reverse transcriptase. The first strand cDNA synthesis reaction was diluted 25-fold so that there was an equivalent of $20 \mathrm{ng}$ of input RNA per microliter. Quantitative PCR assays were carried out in $15 \mu \mathrm{L}$ reaction volumes of iQ SYBR Green Supermix with cDNA equivalent to $100 \mathrm{ng}$ of input RNA. All cDNA samples were assayed in duplicate. Absolute quantification was used to measure gene expression in sheep muscle RNA. The quantitative PCR primers and the plasmid standards were designed and tested according to the methods described previously [24]. Primer sequences are listed in Additional file 1. Cloned amplicons were used as standards to calculate a regression of threshold cycle on molecule copy number to determine a log value of starting abundance for each of the cDNA samples based on their threshold cycle [13]. All plasmid standards were diluted from either $1 \times 10^{8}$ to $1 \times 10^{2}$ or $1 \times 10^{7}$ to $1 \times 10^{1}$ molecules. Quantitative PCR reactions for standards were performed in triplicate. The variance analysis was performed using SAS 9.2 (SAS Institute Inc., Cary, NC, USA) software and the MIXED procedure was used to analyze the log value of gene expression. Genotype was the main effect in the model and each muscle was analyzed individually. The random effect was defined as animal nested within genotype. The least squares means, standard error and difference between least squares means were calculated for the variance analysis.

Relative quantification was used to measure gene expression in DLK-treated myoblast experiments. RNA from cultured myotubes was extracted and purified using Nucleo Spin RNA II columns (Machery-Nagel Inc., Easton, PA USA) with DNase I treatment. First strand cDNA was synthesized from RNA using random hexamer and 
oligo dT priming and MMLV (Life Technologies). Quantitative PCR measurements were performed using the SA Bioscience SYBR Green Supermix (QIAGEN, Valencia, CA USA) reagents on an iCycler Real-Time PCR Detection System (Bio-Rad Inc.). Each reaction was carried out in $15 \mu \mathrm{l}$ reaction volumes of SA Bioscience SYBR Green Supermix with $5 \mathrm{pM}$ of each primer and diluted first-strand cDNA. Primer sequences are listed in Additional file 1. Ribosomal protein large protein 38 (Rplp38) was used as the housekeeping gene control for $\Delta C_{T}$ calculation $\left(\Delta C_{T}=\right.$ $C_{T}$ of the target gene - average $C_{T}$ of housekeeping genes). Fold expression values were calculated using $2^{-\Delta \Delta C T}$ methods [55], where $\Delta \Delta C_{\mathrm{T}}=\left(\Delta C_{T}\right.$ of the treatment sample) $-\left(\Delta C_{T}\right.$ of control treatment samples) with no added DLK1 as control treatment and normalized to 1 . Statistical significance was determined by Analysis of Variance (ANOVA) method using SAS9.2.

\section{Plasmid construction}

Full length DNTTIP1, METTL21E and PARK7 cDNAs were amplified by reverse transcription PCR from total sheep RNA, directionally cloned into pENTR/SD/DTOPO vector (Life Technologies, Grand Island, NY USA) and then subcloned by recombination into the pcDNA3.2/V5-DEST expression vector (Life Technologies), according to the manufacturer's recommendations. The mouse pDLK1-pCMV-SPORT 6.1 plasmid was commercially available (cat\#: MMM1013-9201636, Thermo Fisher Scientific Inc., PA USA). To confirm the insertion of the target genes with an intact open reading frame, all plasmids were sequenced from both directions. The pGWCAT-pcDNA3.2 /V5 control plasmid was obtained from Life Technologies.

The mouse Myh4 luciferase construct (pGL3IIB2.6) contains $2.56 \mathrm{~kb}$ of the promoter region of $M y h 4$, and the rat Myh7 luciferase construct (p-3542 $\beta$-MHCluc) contains $3.5 \mathrm{~kb}$ of the promoter of Myh7 [56, 57]. The pRL-SV40 plasmid expressing renilla luciferase was commercially available from Promega Corporation. Plasmids for electroporation were purified using EndoFree Plasmid Maxi Kit (QIAGEN) and quantified by Nanodrop spectrophotometry (Thermo Fisher Scientific Inc., Rockford, IL USA.

\section{Luciferase reporter assay}

Neon ${ }^{\text {ma }}$ Transfection System (Life Technologies) was used according to the manufacturer's recommended protocol. Myoblasts $\left(2 \times 10^{5}\right.$ cells $)$ were electroporated with $3 \mu \mathrm{g}$ of plasmid DNA with three pulses $10 \mathrm{~ms}$ pulses of $1500 \mathrm{~V}$. To determine if target genes could have effects on myosin gene expression, the effector experiments were performed by cotransfection of protein coding sequence of the target genes along with the myosin luciferase reporter construct. The myosin luciferase reporter construct and the transfection control (renilla luciferase) were kept constant first, and the two different amounts of effector cDNA were titrated. In order to keep a constant amount of the total plasmid DNA, the GW-CAT was added and also used as the null control vector. A detailed description of the plasmid combinations are given in Additional file 2. The electroporated cells were put into 96-well plates in growth media overnight and subsequently fused into myotubes for 3 days. In Park7 luciferase experiments, the indicated concentrations of IGF1 (50, 100, and $200 \mathrm{ng} / \mathrm{mL}$ ) (long ${ }^{\circ}$ R IGF1, Sigma-Aldrich Co, St Louis, MO USA) were added to the fusion medium $24 \mathrm{~h}$ after differentiation and cultured for another $48 \mathrm{~h}$. The reporter assays were performed with Dual-Luciferase Reporter Assay System (Promega, Madison, WI USA), according to the manufacturer's recommendations. The samples were read with a Tecan Genios Pro (Tecan Group Ltd.) plate reader. Luciferase activity was adjusted for transfection efficiency by multiplying the firefly luciferase activity of a given well by the ratio of mean renilla luciferase activity for all wells divided by renilla luciferase activity of the given well to produce units of adjusted luciferase activity. The results were analyzed for the addition of target construct as the main effect by ANOVA using SAS 9.2 software. The IGF1 treatment was also considered as a main effect when analyzing PARK7 luciferase assay.

\section{Results}

\section{Phenotypic data analysis}

Animal birth weight and live weight were collected (Fig. 1) and statistical analysis showed that there were no significant differences in birth weight and live weight between callipyge $(+/ \mathrm{C})$ and normal lambs $(+/+)$. The callipyge lambs had significantly heavier longissimus dorsi, semimembranosus, semitendinosus and triceps brachi, ranging from $23 \%$ to $17 \%$ greater relative to muscles of normal lambs (Fig. 1), thus these four muscles are referred to as "hypertrophied muscles" in this study. No significant differences were detected in supraspinatus, infraspinatus, and heart; hereafter these are referred to as "non-hypertrophied muscles". These results verified the muscle specific phenotype of hypertrophy in the experimental samples.

\section{Muscle specific gene expression}

The mRNA abundance of the 25 differentially expressed transcripts identified from a previous study [24] were assayed by quantitative PCR. To investigate the shift of myosin heavy chain isoforms in callipyge animals, four myosin heavy chain genes (MYH1, MYH2, MYH4, MYH7) were also examined in this study. The complete set of primers for all of the genes analyzed by quantitative PCR and the PCR cycling conditions were given in Additional file 1. The least-square means for gene expression in all seven muscles was given in 


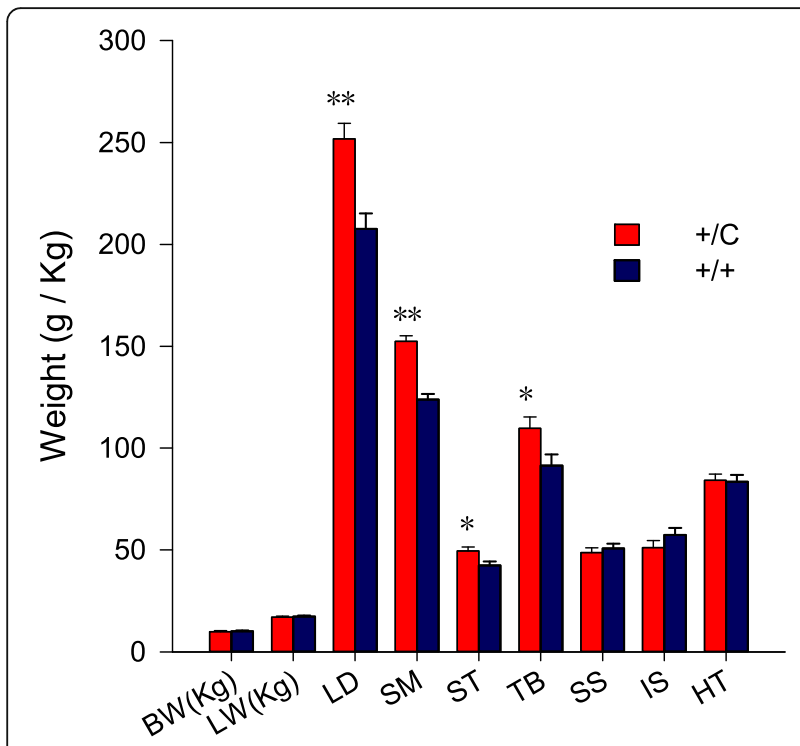

Fig. 1 Muscle hypertrophy in callipyge sheep. There were no differences in the birth weights (BW) and live weights (LW) between callipyge (+/C) and normal lambs (+/+). Callipyge lambs had significantly heavier longissimus dorsi (LD), semimembranosus (SM), semitendinosus (ST) and triceps brachii (TB) muscles. There were no differences in muscle weights for the supraspinatus (SS), infraspinatus (IS) and heart (HT). Significant differences are indicated by $(* ; P<0.05$, or **; $P<0.01)$ between callipyge and normal lambs within each muscle
Additional file 3. The $p$-values for differential expressed genes in seven muscles were listed in Additional file 4.

The expression of Ribosomal protein, large PO (RPLPO) was used as a control gene. RPLPO expression was not significantly different in the two genotypes in all seven muscles (Additional file 5), which indicated that equivalent amounts of RNA were used for cDNA synthesis and for quantitative PCR. Compared to normal lambs, the expression of $D L K 1$ was significantly increased in hypertrophied muscles with semimembranosus having the largest magnitude of increase (11-fold); and triceps brachi had the smallest increase (6.6-fold). There were no significant differences in supraspinatus, infraspinatus and heart (Fig. 2a). In contrast to DLK1, RTL1 expression in normal lambs was extremely low in longissimus dorsi, semitendinosus, triceps brachi and supraspinatus with an average log value of 1.14, and its expression level was barely detectable in semimembranosus, infraspinatus and heart with average log value is less than 1 (Fig. 2b). The expression of RTL1 was significantly increased in callipyge lambs in all the assayed muscles with an average $\log$ value for 4.6. The expression patterns of MEG3 and MEG8 were quite similar since both of their expression levels were significantly increased in the hypertrophied muscles (Fig. 2c and d). The callipyge lambs also had significantly increased MEG3 expression (6-fold, $P$ $=0.0323$ ) in supraspinatus (Fig. $2 \mathrm{~d}$ ). There was a trend
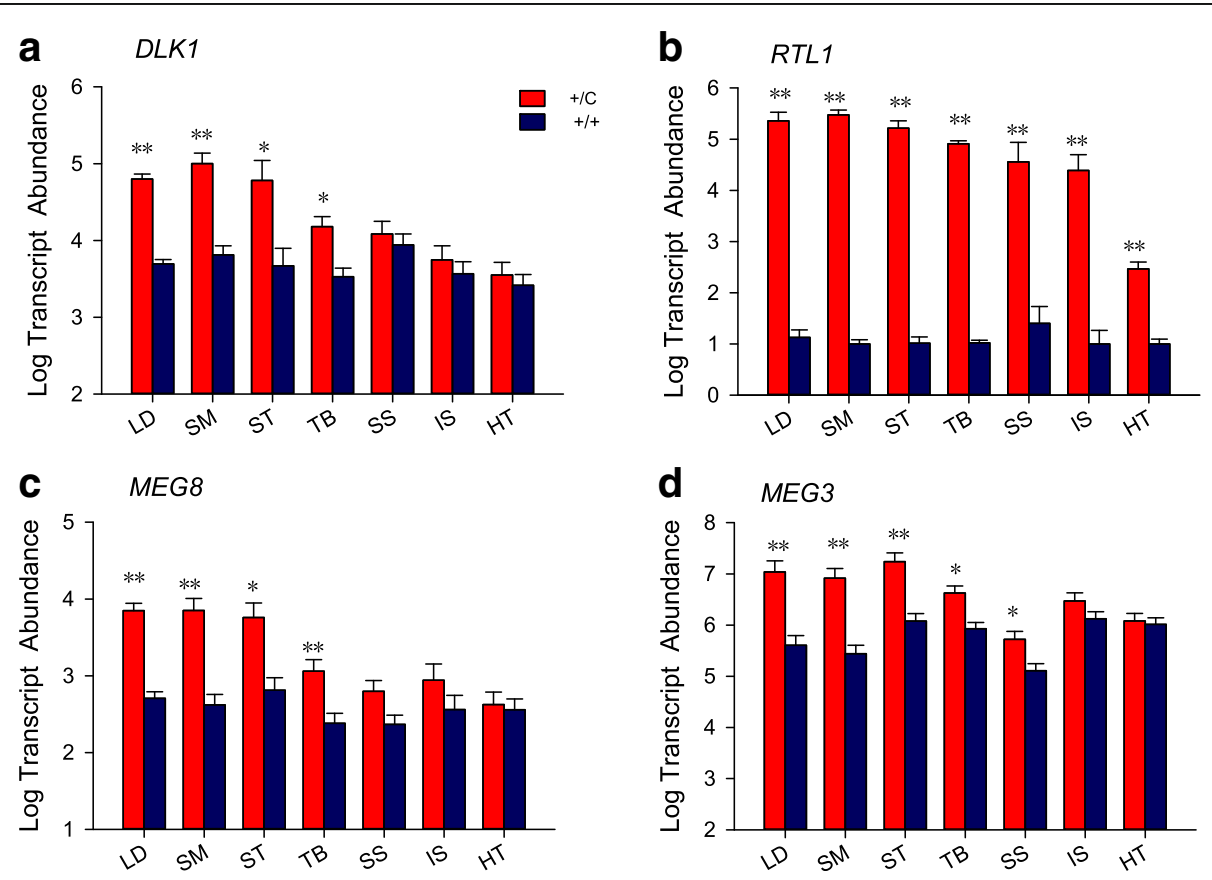

Fig. 2 Transcript abundance of genes from the DLK1-DIO3 locus. a DLK1; b RTL1; c MEG8 and d MEG3. Least square means and standard errors for log transcript abundance are shown for each muscle and genotype, callipyge (+/C) and normal (+/+). The hypertrophied muscles are LD, SM, ST, and TB and the non-hypertrophied muscles are SS, IS and HT. The increased expression of paternally allele-specific genes DLK1 and RTL1, and the maternal allele-specific non-coding RNA MEG8 and MEG3 in callipyge hypertrophied muscles are shown. Significant differences are indicated by (*; $^{*} P<0.05$, or $\left.{ }^{* *} ; P<0.01\right)$ between genotypes within each muscle 
towards significance in $M E G 8$ expression $(P=0.0678)$ (Fig. 2c). The expression patterns of these imprinted genes in the DLK1-DIO3 locus were consistent with previous reports $[13,15]$.

The expression of several myosin isoforms were examined as markers for muscle hypertrophic response. The differential expression of myosin isoforms showed the established fiber type changes in callipyge muscle. A previous study reported the significant and strong upregulation of muscle genes characterized of type IIb $(M Y H 4)$ and down-regulation of genes characterized of type IIa fibers (fast oxidative/glycolytic) (MYH2) and type 1 fibers (slow oxidative) (MYH7) in hypertrophied muscles [53]. The present study confirmed this phenotype by showing an average of 60 -fold increase in $\mathrm{MYH} 4$ expression in the hypertrophied muscles (Fig. 3a). MYH1 is the most abundant myosin isoform measured in the skeletal muscles and its mRNA abundance was significantly increased in semimembranosus by 2.5 -fold (Fig. 3b). MYH2, which characterized an intermediate fiber type between fast and slow fibers, was relatively unchanged in triceps brachi, but down-regulated in other hypertrophied muscles, particularly in longissimus dorsi (6-fold) (Fig. 3c). The mRNA abundance of $M Y H 7$ was only down-regulated in semimembranosus (1.6-fold), which is different from the previous report indicating a decreased level of $M Y H 7$ in longissimus dorsi (Fig. 3d) $[7,9,53]$. Overall, the myosin heavy chain gene expression results confirmed the reported callipyge phenotype with increased fast-glycolytic and decreased slowoxidative myofibers $[9,53]$.

Gene expression profiles for the 23 transcripts, identified from the microarray analysis [24], across the 7 muscle types are shown in Fig. 4. Five genes including Parkinson Protein 7 (PARK7, also known as DJ-1) (Fig. 5a), Deoxynucleotidyltransferase, terminal, interacting protein 1 (DNTTIP1) (Fig. 5b), Solute carrier family 22 member 3 (SLC22A3) (Fig. 5c), protein-lysine methyltransferase 21E (METTL21E) (Fig. 5d), and cAMP specific phophodiesterase 4D (PDE4D) (Fig. 5e) were specifically up-regulated in the hypertrophied muscles, but not in the non-hypertrophied muscles, resembling DLK1 expression pattern. Therefore, these five genes are the potential target genes that may directly respond to DLK1 signaling in hypertrophied muscles. The changes in gene expression of PARK7 in hypertrophied muscles were small relative to the other four genes, but significantly different from normal muscles with semimembranosus having the biggest 6.1-fold increase (Fig. 5a). DNTTIP1 had the biggest magnitude of increase in longissimus dorsi (6.8-fold) and smallest increase in semimembranosus (5.6-fold) (Fig. $5 b)$. There was a substantial up-regulation of $S L C 22 A 3$ in hypertrophied muscles with the magnitude ranging from 8 .

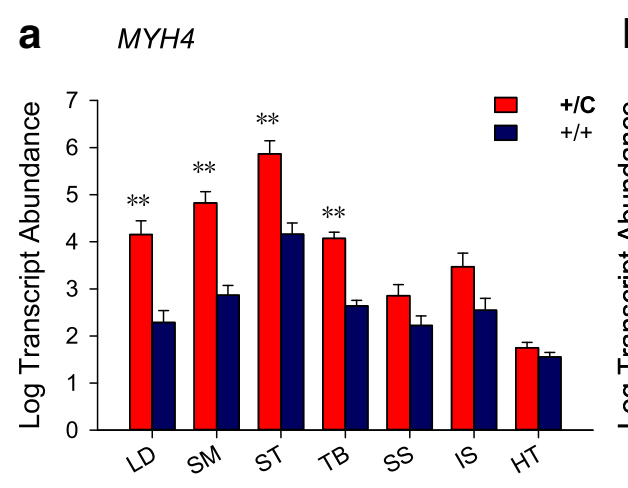

b $\quad$ MYH1
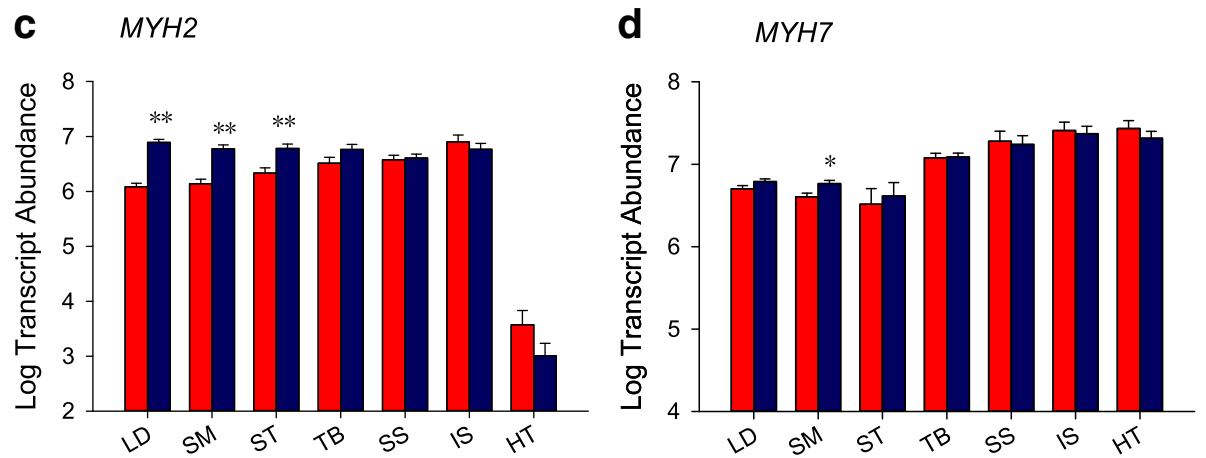

Fig. 3 Transcript abundance of myosin heavy chain genes. a MYH4; $\mathbf{b}$ MYH1; $\mathbf{c}$ MYH2 and $\mathbf{d}$ MYH7. Least square means and standard errors for log transcript abundance in $100 \mathrm{ng}$ of total RNA are shown for each muscle and genotype. Callipyge animals indicated by $+/ C$, and normal animals are represented by +/+. LD, SM, ST, and TB are hypertrophied muscles, SS, IS and HT are non-hypertrophied muscles. Samples are from 30 to 35 days of age lamb. Significant differences are indicated by $\left(* ; P<0.05\right.$, or $\left.{ }^{*} ; P<0.01\right)$ between callipyge and normal lambs within each muscle 


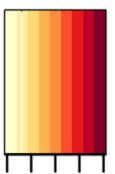

$\begin{array}{lll}-4 & 0 & 4\end{array}$

log2 Fold-change

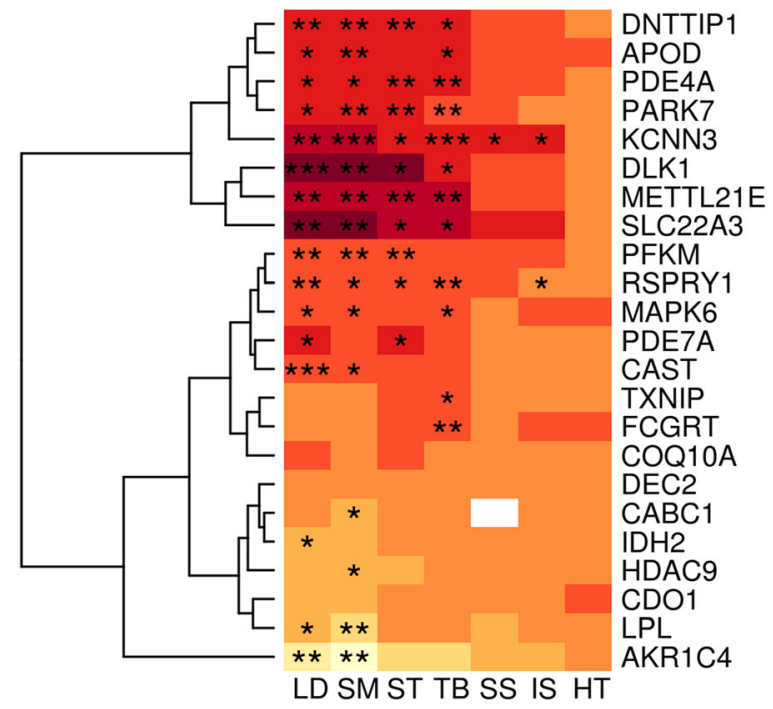

Fig. 4 Hierarchal clustering of candidate gene expression pattern in 7 Muscles. Columns for the seven muscles were fixed and rows representing gene expression were subject to clustering. The fold change of transcript abundance for the ratio of callipyge to normal was transformed to log2. The color scale for this heat map is red-orange-yellow, where the red indicates the magnitude of the fold change in callipyge is higher than normal and yellow represents gene expression was lower in callipyge than normal muscle. Significant differences are indicated by ${ }^{*} P<0.05$, ${ }^{*} P<0.005$ and ${ }^{* * *} P<.0005$ ) between callipyge and normal lambs within each muscle

1-fold to 12.5-fold (Fig. 5c). The average mRNA abundances for METTL21E (Fig. 5d) and PDE4D (Fig. 5e) in hypertrophied muscles were 8.4-fold and 5-fold greater relative to normal lambs. In addition to these five transcripts, a muscle specific expression pattern was observed for all of the genes measured (Fig. 4). In consistent with previous microarray and quantitative PCR study using longissimus dorsi and semimembranosus [24], majority of the 23 transcripts were differentially expressed in these two muscle types in the current study. Many of these genes are metabolic in nature; for example, PFKM (phosphofructokinase, muscle) was up-regulated in three of the four hypertrophied muscles and LPL (Lipoprotein Lipase) was down-regulated in two of the four hypertrophied muscles, therefore they are likely to be involved in response to the changes of $M Y H$ isoforms and metabolic demands in callipyge lambs rather than direct response to $D L K 1$ signaling.

\section{Effects of DLK1 on potential direct target genes and myosin heavy chain gene expression}

In order to examine the effect of DLK1 signaling on the expression of potential target genes, we treated myoblasts and myotubes with recombinant DLK1 protein. Since
C2C12 cells over-expressing Dlk1 failed to proliferate [23], primary myoblasts were plated onto Matrigel containing recombinant DLK1 protein to enable DLK1 to act as ligands for cell surface receptors. Primary myoblasts were induced to fuse and mRNA was collected at $24 \mathrm{~h}$ intervals to a maximum of 3 days (D0, D1, D2 and D3). The expression patterns of myosin heavy chain genes were also examined as controls for cell differentiation. Notably, the expression of most genes examined dramatically reduced 1 day after differentiation (D2 and D3), which may be the result of loss of DLK1 recombinant protein effects after $48 \mathrm{~h}$ (Fig. 6a and b). Therefore, the emphasis was put on data from myoblasts (D0) and myotubes (D1). The mean fold change of each gene for DLK1 treatment was compared to its expression level in control treatment. The mRNA abundance of Dnttip1 was significantly increased by DLK1 treatment in both D0 myoblasts and D1 myotubes (Fig. 6a). Specifically, DLK1-treated D0 myoblasts had 1.4-fold increase in Dnttip1 expression and the DLK1-treated D1 myotubes had 1.7-fold increase. The same trend was also observed for Pde4d expression with 1.4-fold increase in DLK1 treated D0 myoblasts and 1.38fold increase in DLK1 treated D1 myotubes. The 

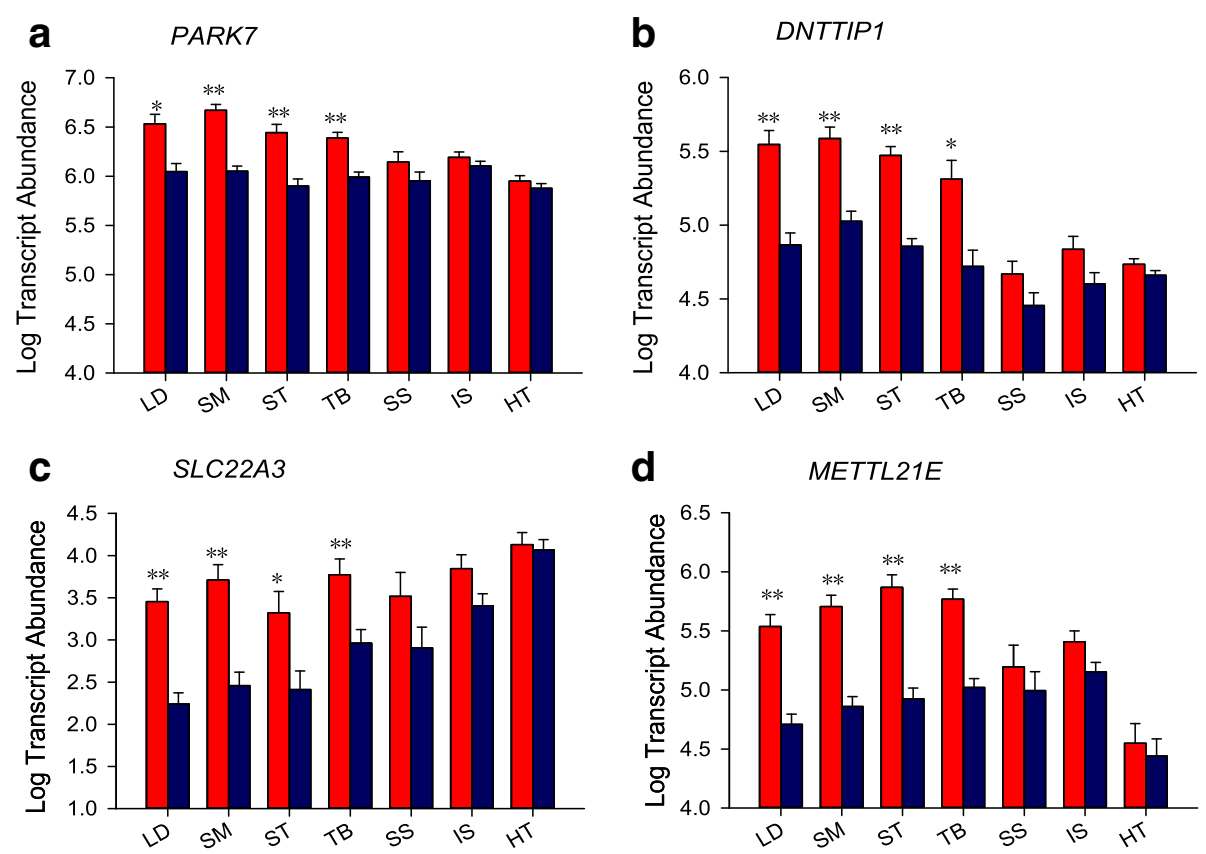

d METTL21E
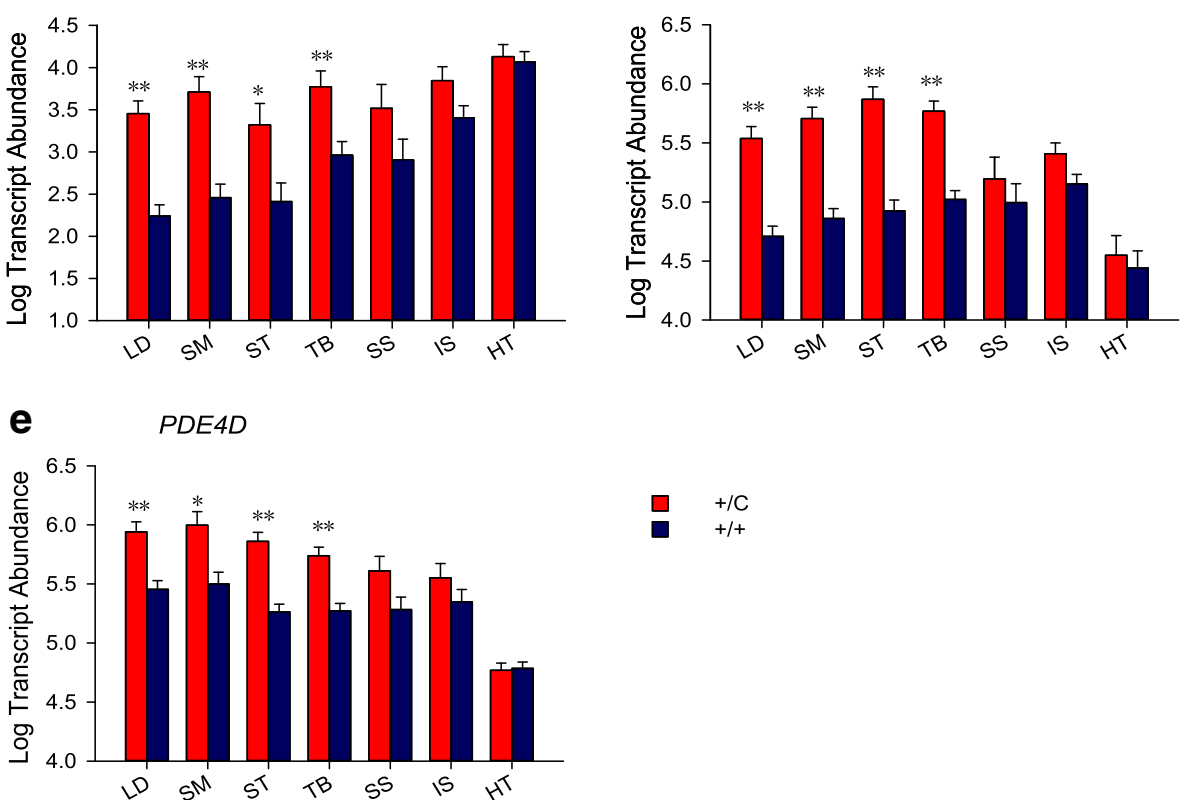

$\square+\begin{array}{ll}+/ C \\ +/+\end{array}$

Fig. 5 Transcript abundance of the candidate target genes in 7 Muscles. a PARK7; b DNTTIP1; c SLC22A3; d METTL21E; and e PDE4D. Least Square means and standard errors for log transcript abundance are shown for each muscle and genotype, callipyge (+/C) and normal (+/+). Five genes exhibited co-expression with DLK1 induced hypertrophy; PARK7, DNTTIP1, SLC22A3, METTL21E, and PDE4D were up-regulated in hypertrophied muscles, LD, SM, ST, and TB but not in the non-hypertrophied muscles SS, IS and HT. Significant differences are indicated by ${ }^{*} ; P<0.05$, or **; $P<0.01$ ) between genotypes within each muscle

expression of Mettl21e has an opposite trend in myoblasts and myotubes with significant increased expression in DLK1- treated D0 myoblasts and significant reduced expression in DLK1-treated D1 myotubes (Fig. 6a). However, the mRNA abundance of Park7 was not significantly changed in the presence of DLK1 (Fig. 6a). Slc22a3 was tested but not reported in this assay since its expression was too low to be reliably quantified. The expression of Myh4 was very low in D0 myoblasts and no significant differences were detected between control and DLK1 treatments (Fig. 6b). However, after differentiation, the mRNA abundance of Myh4 was 1.8-fold $(P<0.0001)$ higher in the DLK1 treated D1 myotubes than control treatment. Surprisingly, the expression of Myh7 was significantly increased in both DLK1-treated myoblasts and myotubes with an average 1.4-fold increase (Fig. 6b), which was opposite to callipyge lambs whose $M Y H 7$ expression are lower than normal lambs. There were no significantly differences between DLK1 treatment and control treatment in Myh1 and Myh2 expression at D0 and D1.

\section{Effects of potential direct target genes on Myh4 and Myh7 luciferase activity}

In order to determine whether PARK7, DNTTIP1, and $M E T T L 21 E$ could influence myosin isoform expression similar to what occurs in callipyge muscle, a series of luciferase assays were conducted to test the effects of these candidate genes on Myh4 and Myh7 promoter activities. The luciferase assays were conducted by cotransfection of the candidate gene cDNA constructs as effector plasmids together with Myh4 (pGL3IIB2.6) or Myh7 (p-3542ß-MHCluc) luciferase reporter plasmids in 


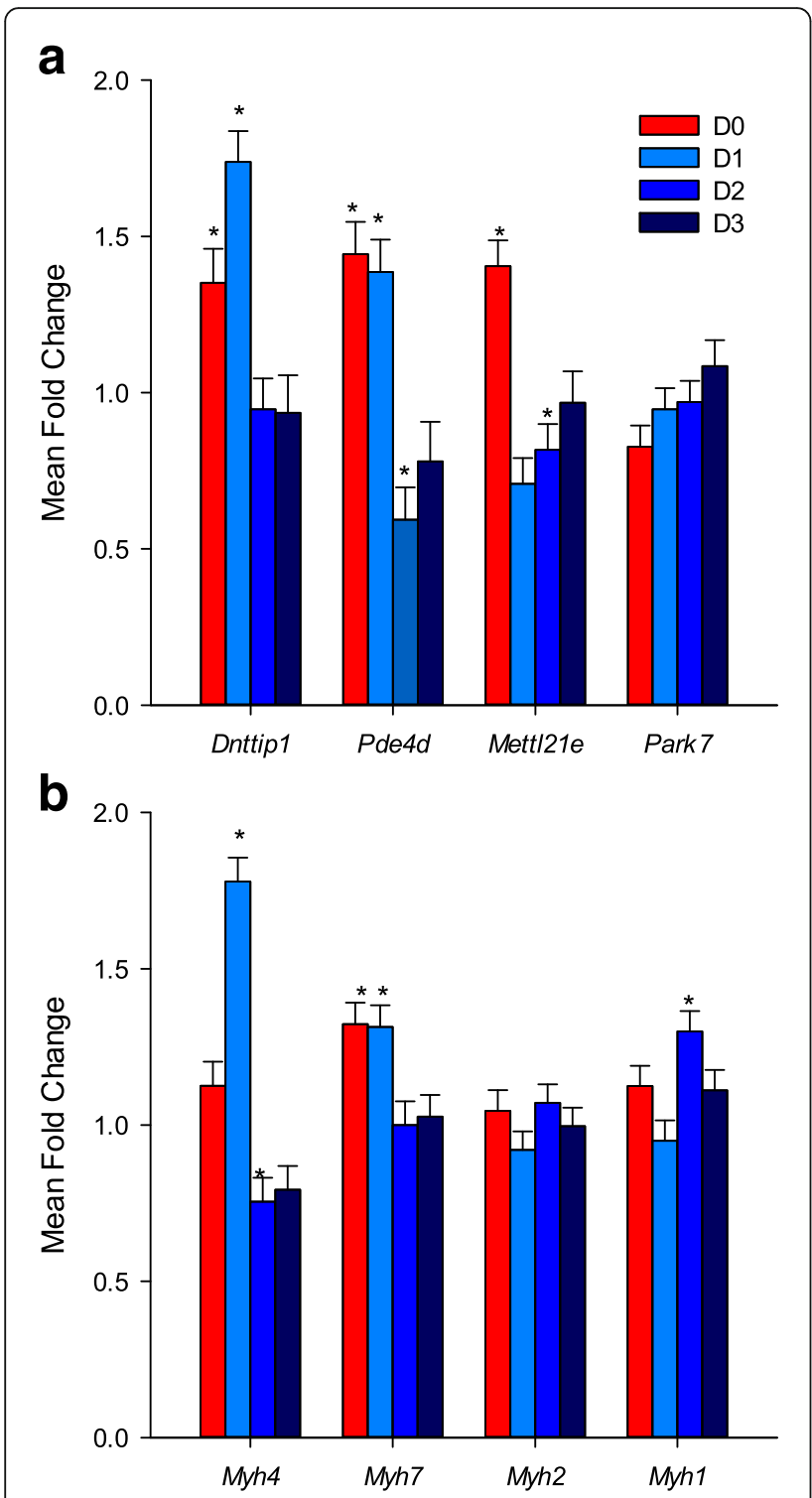

Fig. 6 Transcript abundance of candidate genes and myosin heavy chain genes in DLK1-treated myoblasts and myotubes. Primary myoblasts were cultured on Matrigel (Control) or Matrigel plus recombinant DLK1 protein for $24 \mathrm{~h}$ (D0) and induced to differentiation for up to $72 \mathrm{~h}$. RNA was collected at $24 \mathrm{~h}$ intervals; D0: myoblasts in proliferation medium, D1: 24 h; D2: $48 \mathrm{~h}$ and D3: $72 \mathrm{~h}$ in differentiation medium. a Dnttip1 and Pde4d expression were significantly increased in DLK1 treatment at D0 and D1. Mett/21e expression was highly elevated at D0 but immediately decreased after differentiation (D1). The expression of Park7 was not significantly altered by DLK1 treatment. $\mathbf{b}$ The mRNA abundance of Myh4 was not significantly changed in myoblasts (D0) but was highly elevated after $24 \mathrm{~h}$ of myotube differentiation (D1) with DLK1 treatment. Expression of Myh7 expression was significantly increased in D0 and D1. No significant differences were observed in the expression of Myh2 and Myh1. Significance differences $(* ; P<0.05)$ between control and DLK1 treatment within differentiation time (D0-D3) primary myoblasts. The amount of effector plasmid that was co-transfected was titrated for each plasmid with addition of null vector (pGWCAT) to maintain equal amounts of input DNA. After transfection, myoblasts were differentiated into myotubes for 3 days. The expression of effector protein from the vectors were confirmed by transfection of $\mathrm{C} 2 \mathrm{C} 12$ cells. The cells were stained with corresponding antibodies after transfection (DNTTIP1 in Additional file 6, PARK7 in Additional file 7 and $M E T$ $T L 21 E$ in Additional file 8). These results validated the expression of these constructs and also illustrated the nuclear localization of DNTTIP1, and the nuclear and cytoplasmic localizations of PARK7, METTL21E and GWCAT.

There was a dose effect for $D L K 1$ induced $M y h 4$ luciferase activity. Transfecting $D L K 1$ significantly increased Myh4 luciferase activity at the high concentration (48\%) $(P=0.0012)$ (Fig. 7a). The same effect was also observed in DNTTIP1 treatment; higher concentration $(24 \%)$ of DNTTIP1 resulted in significantly increase in $M y h 4$ luciferase activity $(P<0.0001)$ (Fig. $7 \mathrm{~b})$. In this experiment, less plasmid DNA was used for DNTTIP1 because it was a nuclear factor and predicted to have a strong effect on downstream targets. Conversely, adding METTL21E (60\%) significantly decreased Myh4 luciferase activity $(P=0.0126)$ by $16.5 \%$ (Fig. 7c). An opposite dose response was observed using Myh7 luciferase assay for DLK1 and DNTTIP1 treatments. A $35 \%$ decrease in $M y h 7$ luciferase activity occurred with a high concentration of either DLK1 (48\%) (Fig. 7a) or DNTTIP1 (24\%) (Fig. 7b) treatment. Adding METTL21E, in contrast, significantly increased $M y h 7$ luciferase activity even at a low concentration $(30 \%, P=0.0135$ relative to control) (Fig. 7c).

Since PARK7 was assumed as a positive regulator in the PI3K/AKT pathway, which was initiated by the binding of IGF1 to its receptor $[24,58]$, different concentrations of IGF1 were applied to the myotubes in order to induce a differential response in PARK7 treatment. Statistical analysis indicated the overall effect of $P A R K 7$ was significant in both Myh4 $(P=0.0004)$ (Fig. 8a) and Myh7 $(P<0.0001)$ (Fig. 8b) luciferase assays. Specifically, with a higher concentration of IGF1 $(100 \mathrm{ng} / \mathrm{mL})$ treatment, adding PARK7 even at a low concentration (30\%) significantly increased Myh4 luciferase activity $(P=0.0007)$. There is a similar trend at an IGF1 concentration of $200 \mathrm{ng} / \mathrm{mL}$ with $30 \%$ input of PARK7 significantly increasing Myh4 luciferase activity by $20 \%$ (Fig. 8a). No significant difference was found at low IGF1 concentration $(50 \mathrm{ng} / \mathrm{mL}$ ) and no added IGF1 treatment. There was a dose effect for IGF1 treatment in the Myh4 luciferase assay, however, $M y h 7$ luciferase activity was unaffected by IGF1 treatment. A dose response for PARK7 was observed in PARK7 induced Myh7 luciferase activity. Adding PARK7 (60\%) significantly reduced Myh7 luciferase activity regardless of IGF1 concentrations (Fig. 8b). 


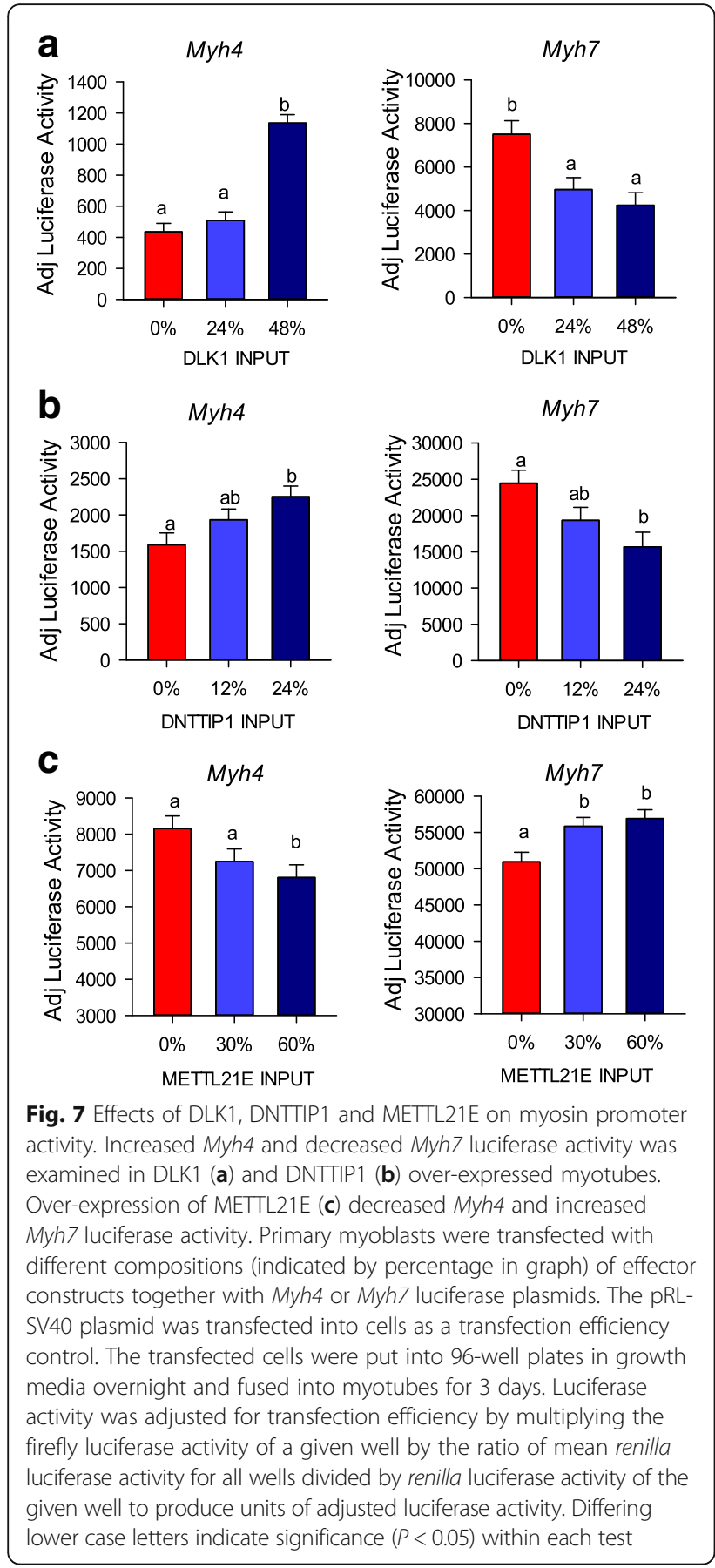

\section{Discussion}

In food animal agriculture, there is a need to identify the mechanisms that can improve the efficiency of muscle growth and protein accretion. Callipyge lambs have improved feed efficiency with greater than $35 \%$ more muscle mass, which shows that much higher muscle growth is biologically possible. Therefore callipyge muscle hypertrophy provides a unique model for investigating the genes that are potentially rate limiting for muscle growth. The transcripts examined in the current study were

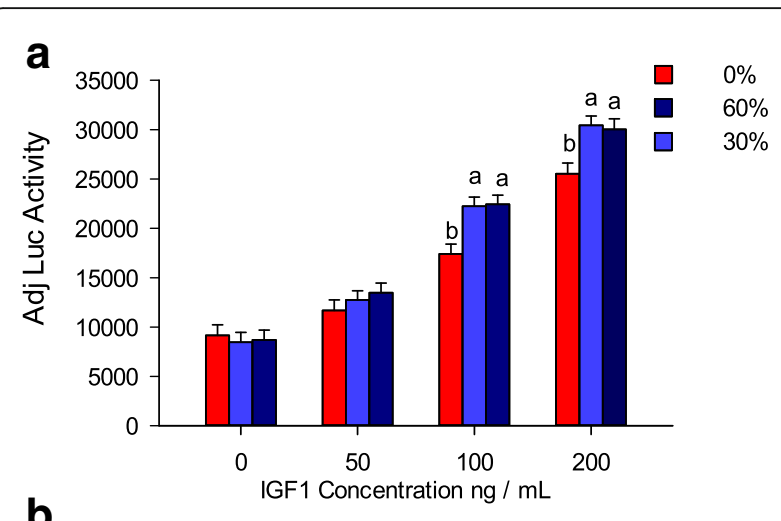

b

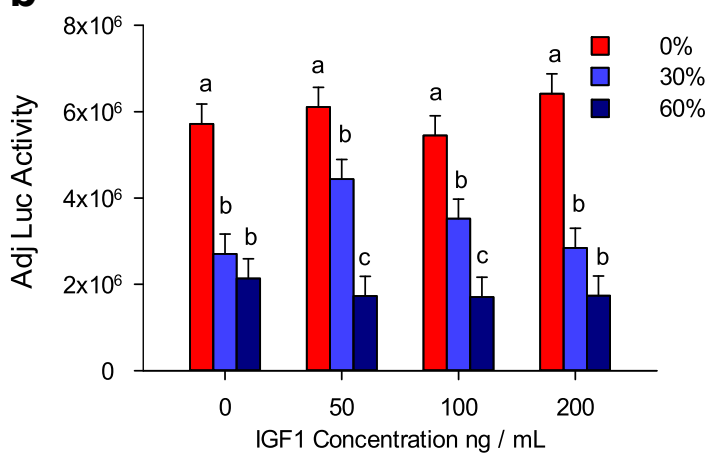

Fig. 8 Effect of PARK7 on myosin promoter activity. Primary myoblasts were transfected with different compositions of effector constructs pPARK7-pcDNA3.2 and pGWCAT- pcDNA3.2 (control) plasmids together with Myh4 or Myh7 luciferase reporter plasmids. The pRL-SV40 plasmid served as a transfection efficiency control. Myosin promoter-luciferase reporter activity was adjusted for transfection efficiency and normalized across all samples on the plate using renilla luciferase activity. a Transfection of PARK7 effector plasmid (input 30\% and 60\%) significantly elevated Myh4 luciferase activity at 100 and $200 \mathrm{ng} / \mathrm{mL}$ concentrations of IGF1; b Transfection of PARK7 plasmid significantly decreased Myh7 luciferase activity regardless of IGF1 concentration. Differing lower case letters indicate significance $(P<0.05)$ within each IGF1 treatment

initially identified and validated in a previous postnatal developmental series (10, 20, 30 days and 80 days) by microarray analyses [24].

The animals in this study reproduced the established phenotype that the callipyge lambs have similar live weights as normal lambs $[4,6]$, and the well-recognized pattern of muscle hypertrophy with increased muscle mass in the pelvic limb and the torso relative to the thoracic limbs [3]. The gene expression analysis in the DLK1-DIO3 locus showed the established pattern for induction of muscle hypertrophy in callipyge lambs. There were high levels of expression of DLK1 and RTL1 in affected muscles from the callipyge lambs. $D L K 1$ was only up-regulated in hypertrophied muscles but the up-regulation of RTL1 was also detected in the three non-hypertrophied muscles. The expression levels of MEG3 and MEG8 were increased in supraspinatus. This combined evidence suggests that RTL1 alone is insufficient to induce muscle hypertrophy and reinforces the 
conclusion that DLK1 is the primary inducer of muscle hypertrophy. Transgenic mice over-expressing either $D l k 1$ or ovine RTL1 have been shown to have increased muscle mass and both genes have been shown to be targets of microRNA hosted by the maternal ncRNA genes in the DLK1-DIO3 imprinted cluster to account for polar overdominance inheritance mechanisms [32]. Therefore, here we include RTL1 as a possible synergistic factor to act in concert with $D L K 1$ to induce the callipyge phenotype.

Analysis of several myosin isoforms showed upregulation of fast twitch glycolytic myosin isoform (MYH4) in all hypertrophied muscles and down-regulation of the fast twitch mixed oxidative and glycolytic myosin isoform (MYH2) in hypertrophied muscles except triceps brachi. The changes in muscle fiber types are indicative for muscle metabolism, which have been reported to be directly associated with elevated postnatal expression of DLK1 protein in muscle fibers [26]. A decrease in slow twitch oxidative $M Y H 7$ was only detected in the semimembranosus but not in other hypertrophied muscles, which is inconsistent with previous observation of the decreases in $M Y H 7$ expression and smaller oxidative myofibers in longissimus dorsi $[7,26$, 53]. The discrepancy is likely due to the younger animals used in the current study, since the decreased level of MYH7 is not evident at $30-35$ days of age.

Among the 23 examined transcripts, five genes, DNTTIP1, PARK7, PDE4D, SLC22A3, and METTL21E, were up-regulated specifically in hypertrophied muscles, resembling DLK1 expression pattern in seven muscles and thus these genes were considered as the secondary targets in response to DLK1 signaling. Only Dnttip1 and Pde4d were up-regulated in DLK1-treated myoblasts and myotubes suggesting a direct signaling effect of DLK1 on the transcriptional expression of these two genes. Taken together, these combined results indicated that DNTTIP1 and PDE4D are potential secondary effector genes responding to $D L K 1$ signaling. The upregulation of Myh4 in DLK1-treated myotubes was consistent with analyses of hypertrophied muscle from callipyge sheep indicating $D L K 1$ signaling have an effect on fast-twitch myofiber formation. DNTTIP1 positively regulated Myh4 and negatively influenced Myh7 luciferase activity, implying a direct effect of the transcription factor on muscle fiber switch in callipyge muscles (Fig. 9b).

Dnttip1 is a transcriptional cofactor that negatively regulates the activity of terminal deoxynucleotidyltransferase (TdT), which is a DNA polymerase synthesizing the Nregion of $\mathrm{B}$ and $\mathrm{T}$-cell receptor genes, independent of a DNA template [59]. Dnttip1 is ubiquitously expressed, exclusively localized in the nucleus and it encodes a protein with a helix-turn-helix and AT-hook-like motif that preferentially binds to AT-rich regions of double-stranded DNA $[59,60]$. This information suggests broader roles of this protein in other tissues. Notably, the promoter region of Myh4 gene contains two AT-rich motifs [61] which indicate that Dnttip1 may bind to the Myh4 promoter region to active its transcription. Moreover, DNTTIP1 is reported to interact with HDAC1 and HDAC2 during $M$ phase [62]. Further protein structural analysis confirmed that DNTTIP1 forms a stoichiometric compex with HDAC1 and the ELM2-SANT domain and is required for the stable assembly of the cyclin A associated MiDAC complex [63]. The HDACs usually down-regulate transcriptional activity by deacetylating histones [64]. The interaction with HDACs may facilitate Dnttip1 regulation of gene expression in muscles. The function of Dnttip1 in muscle growth is unclear.

Both PDE4D and SLC22A3 have increased expression only in hypertrophied muscles, which implied they may play roles in DLK1-induced muscle hypertrophy. The luciferase analysis was not performed for Pde4d in this study due to the confounding expression of numerous alternatively spliced transcripts that dictate subcellular localization and the specific cAMP pools that are affected [65]. Pde4d is a member of phosphodiesterases (PDEs), which catalyze the hydrolysis of cyclic nucleotides cAMP into the inactive substrate 5'-AMP. cAMP

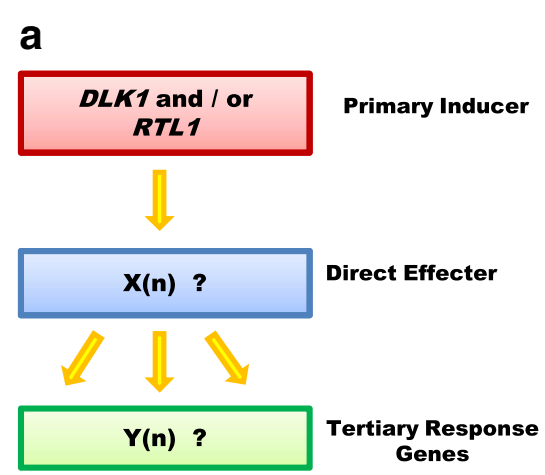

\section{b}

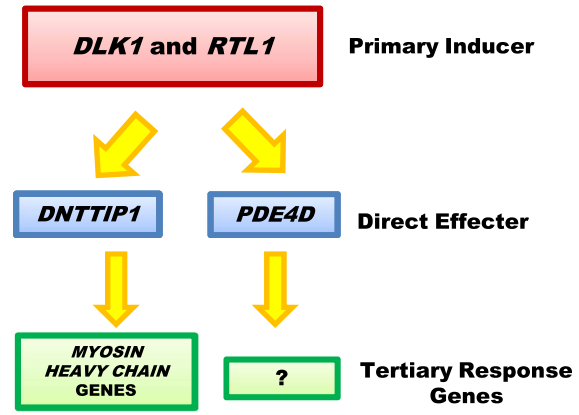

Fig. 9 Schematic diagram showing the hypothesis (a) and conclusions (b) of this study 
signaling is important for muscle hypertrophy and metabolism [66]. The $\beta 2$-adrenergic receptors ( $\beta 2$-ARs) as cAMP inducers in skeletal muscle are of particular importance since they are major targets are $\beta$-agonists. The phenotype observed in callipyge hypertrophy is very similar to muscle growth induced by $\beta$-agonists, which includes increased muscle mass and decreased adiposity [67, 68]. Activation of Pde4d has been shown to be an important feedback regulation system contributing to the transient nature of the $\beta 2$-ARs response and it represents a major adaptive mechanism required for physiological $\beta 2$-ARs signaling [69]. Callipyge lambs do not respond to $\beta$-agonist supplementation with additional muscle hypertrophy [70]. Therefore, the up-regulation of PDE4D in hypertrophied muscles may be associated with a stronger response to physiological levels of adrenaline in young growing lambs.

Slc22a3 / Oct3 (Solute carrier 22A3 / Organic cation transporter 3) is an organic cation transporter and is expressed in a wide range of tissues [71, 72]. By contrast, other two Slc22a gene family members, including Slc22a1 and Slc22a2, are highly expressed in liver and kidney respectively [71]. Slc22a3 knockout mice did not show overt phenotypic abnormalities indicating the loss of Slc22a3 could be potentially compensate by other two members since they share functional similarities by transporting catecholamines and neurotoxin MPP+ (1-methyl-4-phenylpyridinium) [72-76]. Since the knockout mouse model failed to show any skeletal muscle abnormality, we suspect that $S L C 22 A 3$ is not a direct transcriptional response to $D L K 1$ signaling in hypertrophied muscles. Herein, it was excluded from the luciferase study. Slc22a3 mediates the uptake of many important endogenous amines, particularly catecholamines such as norepinephrine and dopamine, and exogenous drugs, such as metformin in a variety of tissues [77-80]. Studies have shown that in excretory organs, such as kidney and liver, Slc22a3 facilitated the uptake of organic cations across the basalateral membrane into the cell $[81,82]$. Slc22a3 is expressed in skeletal muscle [83] but its up-regulation in hypertrophied muscles is now apparent from the current investigation and our earlier studies [24, 53]. It is assumed that the highlevels of SLC22A3 may enhance the up-take of amines including amino acids and biogenic amines that stimulate muscle growth in callipyge lambs. Further studies will be needed to explore its function in muscle development and hypertrophy.

Since Park7 was not up-regulated in DLK1-treated cells, it may not act as a direct transcriptional response to DLK1 signaling but may be a fundamental tertiary response to increased muscle growth. Interestingly, double muscled cattle have elevated levels of PARK7 gene expression and had an increased proportion of white fast-twitch glycolytic fibers as well [84]. With increased PARK7 expression in hypertrophied muscles and its regulation of Myh4 and Myh7 luciferase activity, it may have a physiological role in response to the DLK1-induced muscle hypertrophy. Park7 encodes a ubiquitously expressed, highly conserved protein that was originally identified as an oncogene that transforms NIH3T3 cells in cooperation with the activated ras gene [85]. Park7 has been associated with diverse biological processes including oxidative stress response, transcriptional regulation and cell survival [8688]. Earlier in vitro study showed the significantly larger diameters and more total sarcomeric myosin expression in the Park7 (+/+) myotubes than in the Park7 (-/-) myotubes partially due to the altered activity of the PI3K/AKT pathway [27]. The up-regulation of PARK7 in callipyge lambs may lead to the enhanced activity and/or prolonged sustained activity of the PI3K/AKT pathway and in turn to increase the response of the downstream elements in the PI3K/AKT pathway to increase protein synthesis and muscle mass. Moreover, over-expression of constitutively active AKT resulted in the hypertrophy of glycolytic myofibers not oxidative myobfiers [89]. This study was supported by the identification a regulatory cascade that regulated AKT activation to drive the metabolic and contractile specification of fast-twitch muscle fibers [90]. Therefore, Park7 induced increase in Myh4 luciferase activity could be a result of enhanced activation of AKT.

METTL21E up-regulated Myh7 and down-regulated Myh4 luciferase activity. Although this pattern is different from DLK1, METTL21E may still have a physiological role in callipyge muscle hypertrophy since it is consistently up-regulated in hypertrophied muscles in a manner similar to DLK1. Mettl21e has nuclear localization, but it mostly accumulated in perinuclear cytoplasm (Additional file 8). Hence, it may not act as a direct transcriptional response to $D L K 1$ signaling. The results from the luciferase assay suggested METTL21E may not regulate the myosin heavy chain gene expression, but it may be involved in other biological activities. Accordingly, skeletal muscle has the highest expression level of Mettl21e than any other tissues in mouse (http:// biogps.org/\#goto=genereport\&id=403183). Mettl21e encodes a methyltransferase domain similar to members of the S-adenosylmethionine (SAM) -dependent methyltransferase family [91]. This family of methyltransferases catalyzes the transfer of a methyl group $(\mathrm{CH} 3)$ from a donor, generally S-adenosyl-L-methionine (AdoMet), to various acceptor molecules [92, 93]. In human, there is no METTL21E ortholog, but the bovine METTL21E gene shares $51 \%$ similarity to human METTL21C. Due to the species specificity, the function of Mettl21e is not well defined. However, thousands of substrates of SAMdependent methyltransferases has been identified [94]. These substrates include nucleic acids for regulation of gene expression, DNA or proteins for repair or control of 
signal transduction pathways, hormones and neurotransmitters, and biosynthetic intermediates to produce secondary metabolites [93]. The bioactivities of the substrates may indicate diverse functional roles of METTL21E during the callipyge muscle development.

\section{Conclusions}

In summary, the present study extended knowledge on the genes involved in muscle hypertrophy in the callipyge lambs. The study provided additional support that RTL1 alone was insufficient to induce muscle hypertrophy and concluded that $D L K 1$ was the likely primary inducer of the hypertrophy phenotype. From analyses of DNTTIP1, PARK7, SLC22A3, PDE4D and METTL21E expression, it is proposed that DNTTIP1 and PDE4D are the secondary effector genes responding to DLK1 signaling (Fig. 9b) and DNTTIP1 may respond DLK1 signaling to modulate myosin heavy chain gene expression. We also discovered PARK7 can play a role in muscle fiber switching. Identification of the genes and the signaling pathway that cause the callipyge phenotype will enrich the understanding of postnatal muscle growth in sheep and potentially has application to other livestock species used for meat production.

\section{Additional files}

Additional file 1: Quantitative PCR primer sequences and amplification conditions. (XLSX $13 \mathrm{~kb}$ )

Additional file 2: The plasmids compositions of effector luciferase assay. (XLSX $9 \mathrm{~kb}$ )

Additional file 3: Quantitative analysis of gene expression in 7 muscles (log). (XLSX $16 \mathrm{~kb}$ )

Additional file 4: Analysis of variance of genotype effects in qPCR analysis. (XLSX $14 \mathrm{~kb}$ )

Additional file 5: Transcript abundance of RPLPO in 7 muscles. Least square means and standard errors for log transcript abundance are shown for each muscle and genotype, callipyge (+/C) and normal (+/+). The hypertrophied muscles are LD, SM, ST, and TB and the non-hypertrophied muscles are SS, IS and HT. RPLPO was used as a control to confirm equivalent RNA input into CDNA synthesis and GPCR assays. No significant differences were detected between the two genotypes in all the muscles analyzed. (PDF $21 \mathrm{~kb}$ )

Additional file 6: Cellular localization of DNTTIP1. C2C12 cells were transfected with pDNTTIP1-pCDNA3.2 N5 construct and stained with anti-DNTTIP1 antibody (red), anti-V5 epitope tag antibody (green) and DAPI (nuclei, blue). The merged cells (orange) showed the detection of the same cells by anti-DNTTIP1 and anti-V5 antibodies. DNTTIP1 localized exclusively in nucleus in C2C12 cells. (PDF $43 \mathrm{~kb}$ )

Additional file 7: Cellular localization of PARK7. C2C12 cells were transfected with pPARK7-pcDNA3.2 N5 construct and stained with antiPARK7 (green), anti-V5 epitope tag (red) and DAPI (nuclei, blue). The merged cells (orange) showed the detection of the same cells by antiPARK7 and anti-V5 antibodies. PARK7 localized both in the cytoplasm and nucleus in C2C12 cells. (PDF $69 \mathrm{~kb})$

Additional file 8: Cellular localization of METTL21E and GW-CAT. C2C12 cells were transfected with pMETTL21E-pcDNA3.2 N5 construct (A to C) or pGWCAT- pcDNA3.2N5 (D to F) and stained with anti-METTL21E or anti-GWCAT antibody (green), and DAPI (nuclei, blue). METTL21E (A to C) localized both in the cytoplasm and nucleus but mostly accumulated in cytoplasm in C2C12 cells. GW-CAT (D to F) localized mostly in nucleus. (PDF $51 \mathrm{~kb}$ )

\section{Abbreviations}

ANOVA: Analysis of variance; DIO3: Deiodinase, lodothyronine, type III; DLK1: Deltalike homolog 1; DNTTIP1: Deoxynucleotidyl Transferase Interacting Protein 1; HT: Heart; IS: Infraspinatus; LD: longissimus dorsi; LPL: Lipoprotein Lipase; MEG3: Maternal Expressed Gene 3; MEG8: Maternal Expressed Gene 8; METTL21E: Protein-Lysine Methyltransferase 21E; MYH1: Myosin Heavy Chain 1; MYH2: Myosin Heavy Chain 2; MYH4: Myosin Heavy Chain 4; MYH7: Myosin Heavy Chain 7; PARK7: Parkinson Protein 7; PDE4D: CAMP specific Phophodiesterase 4D; PFKM: Phosphofructokinase, muscle; RPLPO: Ribosomal Protein, large PO; RTL1: Retrotransposon-like 1; RTL1AS: RTL1 antisense; SLC22A3: Solute Carrier Family 22 Member 3; SM: Semimembranosus; SS: Supraspinatus;

ST: Semitendinosus; TB: Triceps brachii

\section{Acknowledgements}

We want to thank Jun Wu for managing the mice colony, Gerald Kelly for his management of the sheep flocks and Dr. Weiyi Liu for his input in experimental techniques. We would like to thank Dr. Swoap and Dr. Hasegawa for kindly providing Myh4 and Myh7 constructs.

\section{Funding}

The work was supported by the Purdue University Agricultural Research Programs and gift funds through the Purdue University Department of Animal Science. The funders had no role in study design, data collection and analysis, decision to publish, or preparation of the manuscript.

\section{Availability of data and materials}

The datasets used and/or analyzed during the current study are available from the corresponding author on reasonable request.

\section{Authors' contributions}

HY designed, performed the experiments, and wrote the paper. JNW sampled lamb muscles and helped with data analysis. SK participated in the experimental design, data analysis, and manuscript preparation. NC conducted genotyping for the lambs. RT and CB participated in expression plasmid construction, experimental design and manuscript preparation. CB was responsible for coordinating the overall project and helping with writing paper. All authors read and approved the final manuscript.

Ethics approval and consent to participate

All of the animals' studies were approved by Purdue University Animal Care and Use Committee (1112000493E001).

\section{Competing interests}

The authors declare that they have no competing interest.

\section{Publisher's Note}

Springer Nature remains neutral with regard to jurisdictional claims in published maps and institutional affiliations.

\section{Author details}

'Department of Animal Sciences, Purdue University, 270 South Russell Street, West Lafayette, IN 47907, USA. ${ }^{2}$ Department of Molecular and Integrative Physiology, University of Michigan, 1000 Wall Street, Ann Arbor, Ml 48105, USA. ${ }^{3}$ Center for Cancer Research, Purdue University, West Lafayette, IN, USA. ${ }^{4}$ CSIRO Animal, Food and Health Sciences, St. Lucia, QLD, Australia.

${ }^{5}$ Department of Animal, Dairy and Veterinary Sciences, Utah State University, Logan, UT, USA. ${ }^{6}$ Department of Animal Science \& Veterinary Technology,

Tarleton State University, Stephenville, TX, USA.

Received: 7 January 2018 Accepted: 16 April 2018

Published online: 24 April 2018

\section{References}

1. Koohmaraie M, Shackelford SD, Wheeler TL, Lonergan SM, Doumit ME. A muscle hypertrophy condition in lamb (callipyge): characterization of effects on muscle growth and meat quality traits. J Anim Sci. 1995;73(12):3596-607.

2. Duckett SK, Snowder GD, Cockett NE. Effect of the callipyge gene on muscle growth, calpastatin activity, and tenderness of three muscles across the growth curve. J Anim Sci. 2000;78(11):2836-41. 
3. Jackson SP, Miller MF, Green RD. Phenotypic characterization of Rambouillet sheep expression the callipyge gene: III. Muscle weights and muscle weight distribution. J Anim Sci. 1997;75(1):133-8.

4. Jackson SP, Green RD, Miller MF. Phenotypic characterization of Rambouillet sheep expressing the callipyge gene: I. Inheritance of the condition and production characteristics. J Anim Sci. 1997;75(1):14-8.

5. Jackson SP, Miller MF, Green RD. Phenotypic characterization of Rambouillet sheep expressing the callipyge gene: II. Carcass characteristics and retail yield. J Anim Sci. 1997;75(1):125-32.

6. Freking BA, Keele JW, Nielsen MK, Leymaster KA. Evaluation of the ovine callipyge locus: II. Genotypic effects on growth, slaughter, and carcass traits. J Anim Sci. 1998;76(10):2549-59.

7. Carpenter CE, Cockett NE. Histology of longissimus muscle from 2-week-old and 8-week-old normal and callipyge lambs. Can J Anim Sci. 2000;80:511-4.

8. Lorenzen $\mathrm{CL}$, Koohmaraie M, Shackelford SD, Jahoor F, Freetly HC, Wheeler TL, Savell JW, Fiorotto ML. Protein kinetics in callipyge lambs. J Anim Sci. 2000;78(1):78-87.

9. Carpenter E, Rice OD, Cockett NE, Snowder GD. Histology and composition of muscles from normal and callipyge lambs. J Anim Sci. 1996;74(2):388-93.

10. Freking BA, Murphy SK, Wylie AA, Rhodes SJ, Keele JW, Leymaster KA, Jirtle $\mathrm{RL}$, Smith TPL. Identification of the single base change causing the callipyge muscle hypertrophy phenotype, the only known example of polar overdominance in mammals. Genome Res. 2002;12(10):1496-506.

11. Smit M, Segers K, Carrascosa LG, Shay T, Baraldi F, Gyapay G, Snowder G, Georges M, Cockett N, Charlier C. Mosaicism of solid gold supports the causality of a noncoding A-to-G transition in the determinism of the callipyge phenotype. Genetics. 2003;163(1):453-6.

12. Bidwell CA, Shay TL, Georges M, Beever JE, Berghmans S, Cockett NE. Differential expression of the GTL2 gene within the callipyge region of ovine chromosome 18. Anim Genet. 2001;32(5):248-56.

13. Bidwell CA, Kramer LN, Perkins AC, Hadfield TS, Moody DE, Cockett NE. Expression of PEG11 and PEG11AS transcripts in normal and callipyge sheep. BMC Biol. 2004;2(17):17.

14. Charlier C, Segers K, Karim L, Shay T, Gyapay G, Cockett N, Georges M. The callipyge mutation enhances the expression of coregulated imprinted genes in cis without affecting their imprinting status. Nat Genet. 2001;27(4): 367-9.

15. Perkins AC, Kramer LN, Spurlock DM, Hadfield TS, Cockett NE, Bidwell CA. Postnatal changes in the expression of genes located in the callipyge region in sheep skeletal muscle. Anim Genet. 2006;37(6):535-42

16. Bidwell CA, Waddell JN, Taxis TM, Yu H, Tellam RL, Neary MK, Cockett NE. New insights into polar overdominance in callipyge sheep. Anim Genet. 2014;45(Suppl 1):51-61.

17. Bray SJ, Takada S, Harrison E, Shen SC, Ferguson-Smith AC. The atypical mammalian ligand Delta-like homologue 1 (Dlk1) can regulate notch signalling in drosophila. BMC Dev Biol. 2008;8:11.

18. Baladron V, Ruiz-Hidalgo MJ, Nueda ML, Diaz-Guerra MJM, Garcia-Ramirez JJ, Bonvini E, Gubina E, Laborda J. dlk acts as a negative regulator of Notch1 activation through interactions with specific EGF-like repeats. Exp Cell Res. 2005;303(2):343-59.

19. Wen Y, Bi P, Liu W, Asakura A, Keller C, Kuang S. Constitutive notch activation upregulates Pax7 and promotes the self-renewal of skeletal muscle satellite cells. Mol Cell Biol. 2012;32(12):2300-11.

20. Nofziger D, Miyamoto A, Lyons KM, Weinmaster G. Notch signaling imposes two distinct blocks in the differentiation of C2C12 myoblasts. Development. 1999;126(8):1689-702.

21. Davis $\mathrm{E}$, Jensen $\mathrm{CH}$, Schroder HD, Farnir F, Shay-Hadfield T, Kliem A, Cockett N, Georges M, Charlier C. Ectopic expression of DLK1 protein in skeletal muscle of padumnal heterozygotes causes the callipyge phenotype. Curr Biol. 2004;14(20):1858-62

22. Gao YQ, Chen X, Wang P, Lu L, Zhao W, Chen C, Chen CP, Tao T, Sun J, Zheng YY, et al. Regulation of DLK1 by the maternally expressed miR-379/ miR-544 cluster may underlie callipyge polar overdominance inheritance. Proc Natl Acad Sci U S A. 2015;112(44):13627-32

23. Waddell JN, Zhang P, Wen Y, Gupta SK, Yevtodiyenko A, Schmidt JV, Bidwell CA, Kumar A, Kuang S. Dlk1 is necessary for proper skeletal muscle development and regeneration. PLoS One. 2010;5(11):e15055.

24. Fleming-Waddell JN, Olbricht GR, Taxis TM, White JD, Vuocolo T, Craig BA Tellam RL, Neary MK, Cockett NE, Bidwell CA. Effect of DLK1 and RTL1 but not MEG3 or MEG8 on muscle gene expression in Callipyge lambs. PLoS One. 2009;4(10):1-15
25. Fleming-Waddell JN, Wilson LM, Olbricht GR, Vuocolo T, Byrne K, Craig BA, Tellam RL, Cockett NE, Bidwell CA. Analysis of gene expression during the onset of muscle hypertrophy in callipyge lambs. Anim Genet. 2007:38(1):28-36.

26. White JD, Vuocolo T, McDonagh M, Grounds MD, Harper GS, Cockett NE, Tellam R. Analysis of the callipyge phenotype through skeletal muscle development; association of Dlk1 with muscle precursor cells. Differentiation. 2008;76(3):283-98.

27. Yu H, Waddell JN, Kuang S, Bidwell CA. Park7 expression influences myotube size and myosin expression in muscle. PLoS One. 2014;9(3):e92030.

28. Charlier C, Segers K, Wagenaar D, Karim L, Berghmans S, Jaillon O, Shay T, Weissenbach J, Cockett N, Gyapay G, et al. Human-ovine comparative sequencing of a 250-kb imprinted domain encompassing the callipyge (clpg) locus and identification of six imprinted transcripts: DLK1, DAT, GTL2, PEG11, antiPEG11, and MEG8. Genome Res. 2001;11(5):850-62.

29. Byrne K, Colgrave ML, Vuocolo T, Pearson R, Bidwell CA, Cockett NE, Lynn DJ, Fleming-Waddell JN, Tellam RL. The imprinted retrotransposon-like gene PEG11 (RTL1) is expressed as a full-length protein in skeletal muscle from Callipyge sheep. PLoS One. 2010;5(1):e8638.

30. Sekita Y, Wagatsuma H, Nakamura K, Ono R, Kagami M, Wakisaka N, Hino T, Suzuki-Migishima R, Kohda T, Ogura A, et al. Role of retrotransposon-derived imprinted gene, Rtl1, in the feto-maternal interface of mouse placenta. Nat Genet. 2008;40(2):243-8.

31. Riordan JD, Keng WW, Tschida BR, Scheetz TE, Bell JB, Podetz-Pedersen KM, Moser CD, Copeland NG, Jenkins NA, Roberts LR, et al. Identification of rtl1, a retrotransposon-derived imprinted gene, as a novel driver of hepatocarcinogenesis. PLoS Genet. 2013;9(4):e1003441.

32. Xu X, Ectors F, Davis EE, Pirottin D, Cheng H, Farnir F, Hadfield T, Cockett N, Charlier C, Georges M, et al. Ectopic expression of retrotransposon-derived PEG11/RTL1 contributes to the Callipyge muscular hypertrophy. PLoS One 2015;10(10):e0140594.

33. Caiment F, Charlier C, Hadfield T, Cockett N, Georges M, Baurain D. Assessing the effect of the CLPG mutation on the microRNA catalog of skeletal muscle using high-throughput sequencing. Genome Res. 2010; 20(12):1651-62.

34. Balik V, Srovnal J, Sulla I, Kalita O, Foltanova T, Vaverka M, Hrabalek L, Hajduch M. MEG3: a novel long noncoding potentially tumour-suppressing RNA in meningiomas. J Neuro-Oncol. 2013;112(1):1-8.

35. Zhou Y, Zhang X, Klibanski A. MEG3 noncoding RNA: a tumor suppressor. J Mol Endocrinol. 2012;48(3):R45-53.

36. Cui $X$, Jing $X$, Long C, Tian J, Zhu J. Long noncoding RNA MEG3, a potential novel biomarker to predict the clinical outcome of cancer patients: a metaanalysis. Oncotarget. 2017:8(12):19049-56.

37. Zhang L, Liang X, Li Y. Long non-coding RNA MEG3 inhibits cell growth of gliomas by targeting miR-93 and inactivating PI3K/AKT pathway. Oncol Rep. 2017;38(4):2408-16.

38. Zhang CY, Yu MS, Li X, Zhang Z, Han CR, Yan B. Overexpression of long non-coding RNA MEG3 suppresses breast cancer cell proliferation, invasion, and angiogenesis through AKT pathway. Tumour Biol. 2017;39(6): 1010428317701311.

39. Xiu YL, Sun KX, Chen X, Chen S, Zhao Y, Guo QG, Zong ZH. Upregulation of the IncRNA Meg3 induces autophagy to inhibit tumorigenesis and progression of epithelial ovarian carcinoma by regulating activity of ATG3. Oncotarget. 2017;8(19):31714-25.

40. Tong GF, Qin N, Sun LW, Xu XL. Long noncoding RNA MEG3 suppresses glioma cell proliferation, migration, and invasion by acting as competing endogenous RNA of MiR-19a. Oncol Res. 2017;25(9):1471-1478(8).

41. Wang X, Wang Z, Wang J, Wang Y, Liu L, Xu X. LncRNA MEG3 has antiactivity effects of cervical cancer. Biomed Pharmacother. 2017;94:636-43.

42. Zhu X, Wu YB, Zhou J, Kang DM. Upregulation of IncRNA MEG3 promotes hepatic insulin resistance via increasing FoxO1 expression. Biochem Biophys Res Commun. 2016;469(2):319-25.

43. Oczkowicz M, Piestrzyska-Kajtoch A, Piorkowska K, Rejduch B, Rozycki M. Expression of DLK1 and MEG3 genes in porcine tissues during postnatal development. Genet Mol Biol. 2010;33(4):790-4.

44. Butchart LC, Fox A, Shavlakadze T, Grounds MD. The long and short of noncoding RNAs during post-natal growth and differentiation of skeletal muscles: focus on IncRNA and miRNAs. Differentiation. 2016;92(5):237-48.

45. Gu T, He H, Han Z, Zeng T, Huang Z, Liu Q, Gu N, Chen Y, Sugimoto K, Jiang $\mathrm{H}$, et al. Expression of macro non-coding RNAs Meg8 and Irm in mouse embryonic development. Acta Histochem. 2012;114(4):392-9. 
46. Wang $X$, Lan $X$, Radunz AE, Khatib H. Maternal nutrition during pregnancy is associated with differential expression of imprinted genes and DNA methyltranfereases in muscle of beef cattle offspring. J Anim Sci. 2015;93(1):35-40.

47. Lan X, Cretney EC, Kropp J, Khateeb K, Berg MA, Penagaricano F, Magness R, Radunz $A E$, Khatib $H$. Maternal diet during pregnancy induces gene expression and DNA methylation changes in fetal tissues in sheep. Front Genet. 2013:4:49

48. Beygo J, Kuchler A, Gillessen-Kaesbach G, Albrecht B, Eckle J, Eggermann T, Gellhaus A, Kanber D, Kordass U, Ludecke HJ, et al. New insights into the imprinted MEG8-DMR in 14q32 and clinical and molecular description of novel patients with temple syndrome. Eur J Hum Genet. 2017;25(8):935-45.

49. Bens S, Kolarova J, Gillessen-Kaesbach G, Buiting K, Beygo J, Caliebe A Ammerpohl O, Siebert R. The differentially methylated region of MEG8 is hypermethylated in patients with temple syndrome. Epigenomics. 2015;7(7):1089-97.

50. Seitz H, Youngson N, Lin SP, Dalbert S, Paulsen M, Bachellerie JP, FergusonSmith AC, Cavaille J. Imprinted microRNA genes transcribed antisense to a reciprocally imprinted retrotransposon-like gene. Nat Genet. 2003:34(3):261-2

51. Davis E, Caiment F, Tordoir X, Cavaille J, Ferguson-Smith A, Cockett N, Georges M, Charlier C. RNAi-mediated allelic trans-interaction at the imprinted Rtl1/Peg11 locus. Curr Biol. 2005;15(9):743-9.

52. Ito M, Sferruzzi-Perri AN, Edwards CA, Adalsteinsson BT, Allen SE, Loo TH, Kitazawa M, Kaneko-Ishino T, Ishino F, Stewart CL, et al. A trans-homologue interaction between reciprocally imprinted miR-127 and Rtl1 regulates placenta development. Development. 2015;142(14):2425-30.

53. Vuocolo T, Byrne K, White J, McWilliam S, Reverter A, Cockett NE, Tellam RL. Identification of a gene network contributing to hypertrophy in callipyge skeletal muscle. Physiol Genomics. 2007;28(3):253-72.

54. Liu W, Wen Y, Bi P, Lai X, Liu XS, Liu X, Kuang S. Hypoxia promotes satellite cell self-renewal and enhances the efficiency of myoblast transplantation. Development. 2012;139(16):2857-65.

55. Livak KJ, Schmittgen TD. Analysis of relative gene expression data using real-time quantitative PCR and the 2(-Delta Delta C(T)) method. Methods. 2001;25(4):402-8.

56. Hasegawa K, Lee SJ, Jobe SM, Markham BE, Kitsis RN. Cis-acting sequences that mediate induction of beta-myosin heavy chain gene expression during left ventricular hypertrophy due to aortic constriction. Circulation. 1997: 96(11):3943-53.

57. Swoap SJ. In vivo analysis of the myosin heavy chain IIB promoter region. Am J Phys. 1998;274(3 Pt 1):C681-7

58. Kim RH, Peters M, Jang Y, Shi W, Pintilie M, Fletcher GC, DeLuca C, Liepa J, Zhou L, Snow B, et al. DJ-1, a novel regulator of the tumor suppressor PTEN. Cancer Cell. 2005;7(3):263-73.

59. Yamashita N, Shimazaki N, Ibe S, Kaneko R, Tanabe A, Toyomoto T, Fujita K, Hasegawa T, Toji S, Tamai K, et al. Terminal deoxynucleotidyltransferase directly interacts with a novel nuclear protein that is homologous to p65. Genes Cells. 2001;6(7):641-52.

60. Kubota T, Maezawa S, Koiwai K, Hayano T, Koiwai O. Identification of functional domains in TdIF1 and its inhibitory mechanism for TdT activity. Genes Cells. 2007;12(8):941-59.

61. Takeda S, North DL, Lakich MM, Russell SD, Whalen RG. A possible regulatory role for conserved promoter motifs in an adult- specific muscle myosin gene from mouse. J Biol Chem. 1992;267(24):16957-67.

62. Bantscheff M, Hopf C, Savitski MM, Dittmann A, Grandi P, Michon AM, Schlegl J, Abraham Y, Becher I, Bergamini G, et al. Chemoproteomics profiling of HDAC inhibitors reveals selective targeting of HDAC complexes. Nat Biotechnol. 2011;29(3):255-65.

63. Itoh T, Fairall L, Muskett FW, Milano CP, Watson PJ, Arnaudo N, Saleh A, Millard CJ, El-Mezgueldi M, Martino F, et al. Structural and functional characterization of a cell cycle associated HDAC1/2 complex reveals the structural basis for complex assembly and nucleosome targeting. Nucleic Acids Res. 2015;43(4):2033-44.

64. Segre CV, Chiocca S. Regulating the regulators: the post-translational code of class I HDAC1 and HDAC2. J Biomed Biotechnol. 2011;2011:690848.

65. Richter W, Jin SL, Conti M. Splice variants of the cyclic nucleotide phosphodiesterase PDE4D are differentially expressed and regulated in rat tissue. Biochem J. 2005:388(Pt 3):803-11.

66. Berdeaux R, Stewart R. cAMP signaling in skeletal muscle adaptation: hypertrophy, metabolism, and regeneration. Am J Physiol Endocrinol Metab. 2012;303(1):E1-17
67. Kretchmar DH, Hathaway MR, Epley RJ, Dayton WR. Alterations in postmortem degradation of myofibrillar proteins in muscle of lambs fed a beta-adrenergic agonist. J Anim Sci. 1990;68(6):1760-72.

68. Pringle TD, Calkins CR, Koohmaraie $M$, Jones SJ. Effects over time of feeding a beta-adrenergic agonist to wether lambs on animal performance, muscle growth, endogenous muscle proteinase activities, and meat tenderness. J Anim Sci. 1993;71(3):636-44.

69. Liu H, Palmer D, Jimmo SL, Tilley DG, Dunkerley HA, Pang SC, Maurice DH. Expression of phosphodiesterase 4D (PDE4D) is regulated by both the cyclic AMP-dependent protein kinase and mitogen-activated protein kinase signaling pathways. A potential mechanism allowing for the coordinated regulation of PDE4D activity and expression in cells. J Biol Chem. 2000; 275(34):26615-24

70. Koohmaraie M, Shackelford SD, Wheeler TL. Effects of a beta-adrenergic agonist $(L-644,969)$ and male sex condition on muscle growth and meat quality of callipyge lambs. J Anim Sci. 1996;74(1):70-9.

71. Nies AT, Koepsell H, Damme K, Schwab M. Organic cation transporters (OCTs, MATEs), in vitro and in vivo evidence for the importance in drug therapy. Handb Exp Pharmacol. 2011;201:105-67.

72. Zwart R, Verhaagh S, Buitelaar M, Popp-Snijders C, Barlow DP. Impaired activity of the extraneuronal monoamine transporter system known as uptake-2 in Orct3/SIc22a3-deficient mice. Mol Cell Biol. 2001;21(13):4188-96.

73. Verhaagh S, Schweifer N, Barlow DP, Zwart R. Cloning of the mouse and human solute carrier 22a3 (SIc22a3/SLC22A3) identifies a conserved cluster of three organic cation transporters on mouse chromosome 17 and human 6q26-q27. Genomics. 1999;55(2):209-18.

74. Breidert T, Spitzenberger F, Grundemann D, Schomig E. Catecholamine transport by the organic cation transporter type 1 (OCT1). Br J Pharmacol. 1998;125(1):218-24.

75. Grundemann D, Koster S, Kiefer N, Breidert T, Engelhardt M, Spitzenberger F Obermuller N, Schomig E. Transport of monoamine transmitters by the organic cation transporter type 2, OCT2. J Biol Chem. 1998;273(47):30915-20.

76. Grundemann D, Schechinger B, Rappold GA, Schomig E. Molecular identification of the corticosterone-sensitive extraneuronal catecholamine transporter. Nat Neurosci. 1998;1(5):349-51.

77. Chen L, Hong C, Chen EC, Yee SW, Xu L, Almof EU, Wen C, Fujii K, Johns SJ, Stryke D, et al. Genetic and epigenetic regulation of the organic cation transporter 3, SLC22A3. Pharmacogenomics J. 2013;13(2):110-20.

78. Ayala-Lopez N, Jackson WF, Burnett R, Wilson JN, Thompson JM, Watts SW. Organic cation transporter 3 contributes to norepinephrine uptake into perivascular adipose tissue. Am J Physiol Heart Circ Physiol. 2015;309(11):H1904-14

79. Chen L, Pawlikowski B, Schlessinger A, More SS, Stryke D, Johns SJ, Portman MA, Chen E, Ferrin TE, Sali A, et al. Role of organic cation transporter 3 (SLC22A3) and its missense variants in the pharmacologic action of metformin. Pharmacogenet Genomics. 2010;20(11):687-99.

80. Chen EC, Liang X, Yee SW, Geier EG, Stocker SL, Chen L, Giacomini KM. Targeted disruption of organic cation transporter 3 attenuates the pharmacologic response to metformin. Mol Pharmacol. 2015;88(1):75-83.

81. Ahmadimoghaddam D, Zemankova L, Nachtigal P, Dolezelova $E$, Neumanova Z, Cerveny L, Ceckova M, Kacerovsky M, Micuda S, Staud F. Organic cation transporter 3 (OCT3/SLC22A3) and multidrug and toxin extrusion 1 (MATE1/SLC47A1) transporter in the placenta and fetal tissues: expression profile and fetus protective role at different stages of gestation. Biol Reprod. 2013;88(3):55.

82. Ahmadimoghaddam D, Hofman J, Zemankova L, Nachtigal P, Dolezelova $E$, Cerveny L, Ceckova M, Micuda S, Staud F. Synchronized activity of organic cation transporter 3 (Oct3/Slc22a3) and multidrug and toxin extrusion 1 (Mate1/Slc47a1) transporter in transplacental passage of MPP+ in rat. Toxicol Sci. 2012;128(2):471-81.

83. Lee WK, Wolff NA, Thevenod F. Organic cation transporters: physiology, toxicology and special focus on ethidium as a novel substrate. Curr Drug Metab. 2009:10(6):617-31.

84. Chelh I, Picard B, Hocquette JF, Cassar-Malek I. Myostatin inactivation induces a similar muscle molecular signature in double-muscled cattle as in mice. Animal. 2011;5(2):278-86.

85. Nagakubo D, Taira T, Kitaura H, Ikeda M, Tamai K, Iguchi-Ariga SM, Ariga H. DJ-1, a novel oncogene which transforms mouse NIH3T3 cells in cooperation with ras. Biochem Biophys Res Commun. 1997:231(2):509-13.

86. McNally RS, Davis BK, Clements CM, Accavitti-Loper MA, Mak TW, Ting JP. DJ-1 enhances cell survival through the binding of Cezanne, a negative regulator of NF-kappaB. J Biol Chem. 2011;286(6):4098-106. 
87. Takahashi K, Taira T, Niki T, Seino C, Iguchi-Ariga SM, Ariga H. DJ-1 positively regulates the androgen receptor by impairing the binding of PIASX alpha to the receptor. J Biol Chem. 2001;276(40):37556-63.

88. Tillman JE, Yuan J, Gu G, Fazli L, Ghosh R, Flynt AS, Gleave M, Rennie PS, Kasper S. DJ-1 binds androgen receptor directly and mediates its activity in hormonally treated prostate cancer cells. Cancer Res. 2007; 67(10):4630-7.

89. Izumiya Y, Hopkins T, Morris C, Sato K, Zeng L, Viereck J, Hamilton JA, Ouchi N, LeBrasseur NK, Walsh K. Fast/glycolytic muscle fiber growth reduces fat mass and improves metabolic parameters in obese mice. Cell Metab. 2008;7(2):159-72.

90. Meng ZX, Li S, Wang L, Ko HJ, Lee Y, Jung DY, Okutsu M, Yan Z, Kim JK, Lin JD. Baf60c drives glycolytic metabolism in the muscle and improves systemic glucose homeostasis through Deptor-mediated Akt activation. Nat Med. 2013;19(5):640-5.

91. Marchler-Bauer A, Anderson JB, Derbyshire MK, DeWeese-Scott C, Gonzales NR, Gwadz M, Hao L, He S, Hurwitz DI, Jackson JD, et al. CDD: a conserved domain database for interactive domain family analysis. Nucleic Acids Res. 2007;35(Database issue):D237-40.

92. Martin JL, McMillan FM. SAM (dependent) I AM: the S-adenosylmethioninedependent methyltransferase fold. Curr Opin Struct Biol. 2002;12(6):783-93.

93. Schubert HL, Blumenthal RM, Cheng X. Many paths to methyltransfer: a chronicle of convergence. Trends Biochem Sci. 2003;28(6):329-35.

94. Struck AW, Thompson ML, Wong LS, Micklefield J. S-adenosyl-methioninedependent methyltransferases: highly versatile enzymes in biocatalysis, biosynthesis and other biotechnological applications. Chembiochem. 2012 13(18):2642-55.

Ready to submit your research? Choose BMC and benefit from:

- fast, convenient online submission

- thorough peer review by experienced researchers in your field

- rapid publication on acceptance

- support for research data, including large and complex data types

- gold Open Access which fosters wider collaboration and increased citations

- maximum visibility for your research: over $100 \mathrm{M}$ website views per year

At BMC, research is always in progress.

Learn more biomedcentral.com/submissions 